\title{
LA DISTRIBUCIÓN COMERCIAL (I-2) ASPECTOS CONTRACTUALES
}

\author{
Fernando Carbajo Cascón \\ Doctor en Derecho, Universidad de Salamanca, España; Licenciado en Derecho por la Universidad de Salamanca; \\ Magistrado de la Audiencia Provincial de Salamanca (Tribunal de Apelaciones), España; Profesor Titular de \\ Derecho Mercantil de la Universidad de Salamanca, España. \\ E-mail: nano@usal.es
}

\section{Resumen}

En esta oportunidad y para dar continuidad al desarrollo del tema sobre la Distribución Comercial se presentan, ahora, los aspectos contractuales con carácter específico de los contratos de distribución comercial en sentido estricto, se revisa el contrato de distribución exclusiva o concesión comercial, el contrato de distribución selectiva, el contrato de franquicia y, para finalizar se reflexiona sobre el impacto de Internet para la distribución comercial y nuevas formas de distribución comercial en el mercado virtual.

Palabras clave: Contrato, distribución comercial, derechos y obligaciones, causas de resolución, extinción del contrato, información comercial.

Abstract

In this opportunity, and to keep working on the development so far in this topic about Commercial Distribution, it is shown now, the contractual aspects with about the specific characteristics of the commercial distribution contracts in strict sense. The exclusive distribution or commercial concession contract, selective distribution contract, and franchise contract are reviewed in this paper. At the end, we contemplate the impact of the internet on commercial distribution and new ways of commercial distribution on the virtual market.

Key Words: Contract, commercial distribution, rights and obligations, resolution causes, contract extinction, commercial information.

\section{Résumé}

A cette occasion, et de poursuivre le développement du sujet sur l'entreprise de distribution sont maintenant une question de problèmes contractuels spécifiques des contrats de distribution commerciale au sens strict, nous passons en revue le contrat ou accorder des entreprises de distribution exclusive, le contrat distribution sélective, le contrat de franchise et, enfin, reflète l'impact de l'Internet pour la distribution commerciale et les nouvelles formes de distribution commerciale dans le marché virtuel.

Mots-clés: Contrat, la distribution commerciale, les droits et obligations, les motifs de sa résiliation, la résiliation du contrat, des renseignements commerciaux. 

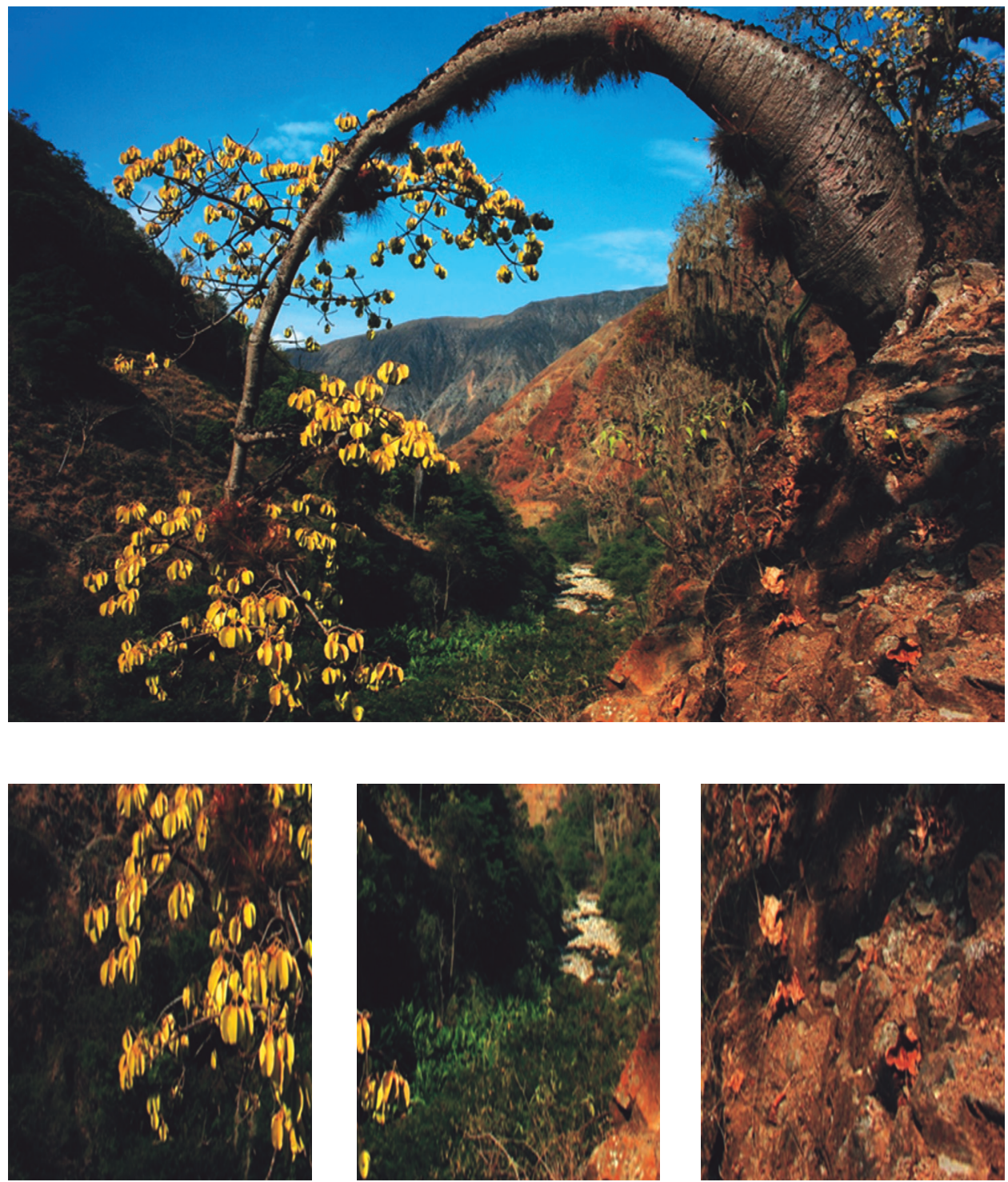

Cañón del Chicamocha - Ceibas Barrigonas

Jorge William Sánchez Latorre 


\section{LA DISTRIBUCIÓN COMERCIAL (I-2) ASPECTOS CONTRACTUALES*}

\section{EL CONTRATO DE DISTRIBUCIÓN EXCLUSIVA O CONCESIÓN COMERCIAL}

\section{Concepto y caracteres fundamentales del contrato}

El contrato de distribución exclusiva o concesión comercial es un contrato legalmente atípico (aunque es definido legalmente y regulado parcialmente en Europa por el Derecho de la libre competencia), aunque de una gran tipicidad económica y social en el mundo actual, por lo que ha sido definido en sus elementos fundamentales por doctrina científica y jurisprudencial. Habitualmente han querido verse en este contrato elementos de la compraventa mercantil y del suministro con pacto de exclusiva ${ }^{1}$, aunque hoy día parece evidente que -aunque reúna elementos propios de la compraventa y el suministro en exclusiva- el contrato de concesión es un contrato sui generis, con sustantividad propia, donde el factor fundamental reside en la existencia de una colaboración económica duradera en forma de integración económica vertical entre las partes ${ }^{2}$.

* De acuerdo con lo enunciado en el número anterior de la publicación, el artículo se enmarca en la línea de Investigación, Organización y Actividad Empresarial del Grupo Neoconstitucionalismo y Derecho, Facultad de Derecho Universidad Santo Tomás- Bucaramanga, en el marco del Convenio de Colaboración conjunta- Universidad Salamanca España. La primera parte (I-1) introductoria al estudio del fenómeno de la distribución comercial desde la perspectiva contractual, considera la viabilidad y conveniencia de incluir la agencia de esta categoría. En la segunda parte (I-2) de este trabajo sobre aspectos contractuales, se ocupa ya con carácter específico de los contratos de distribución comercial en sentido estricto.

1 Cfr., Sentencias del Tribunal Supremo español de 29 de octubre de 1995, 4 de octubre de 1999 y 16 de noviembre de 2000.

2 Vid., entre otros, Puente Muñoz, Ma. T., El contrato de concesión mercantil, Montecorvo, Madrid, 1976; Moralejo Menéndez, I., El contrato mercantil de concesión, cit.; Díaz Echegaray J.L., "El contrato de distribución exclusiva o de concesión", en Bercovitz Rodríguez-Cano, A. / Calzada Conde, Ma. A. (Dir.), Contratos Mercantiles, T. I, Thomson-Reuters Aranzadi, Navarra, 2009, pp. 762 y ss. 
Por el contrato de concesión mercantil o comercial (distribución exclusiva) una parte (fabricante o concedente) autoriza, habilita y concede a otra (distribuidor o concesionario), la posibilidad de integrarse en su red de distribución para adquirir bajo determinadas condiciones sus productos de marca (generalmente una marca notoria o renombrada), con vistas a su posterior reventa a terceros, habitualmente en una zona territorial exclusiva pactada de antemano, valiéndose de la imagen de marca del principal y según las directrices de marketing, calidad y, en su caso, asistencia técnica predispuestas por aquél para toda su red de concesionarios.

A diferencia del agente, el concesionario actúa por su propio nombre y cuenta, adquiere en firme las mercancías suministradas por el concedente para revenderlas bajo la marca de éste último, se lucra con la diferencia y asume todos los gastos y riesgos sobre las mismas, tanto por lo que se refiere al transporte, recepción y almacenamiento, como al cobro y, en su caso, financiación a la clientela; aunque cada vez es más frecuente en determinados sectores la existencia dentro de la red de distribución de entidades de financiación al consumo creadas por el concedente (especialmente en el sector de la automoción). Como se vio, el agente contribuye a la distribución de los productos o servicios del agenciado o principal sin asumir el riesgo de la operación (salvo que se pacte una agencia de garantía) y actúa en todo caso en nombre y por cuenta del proveedor. No obstante, entre ambos se aprecia una conexión funcional evidente, pues -como en la agencia- el concesionario también actúa en interés del concedente (negotiorum gestio). Por eso, aunque la forma jurídica de entablar y desarrollar esa colaboración es muy diferente, tiene sentido la aplicación analógica de parte del régimen jurídico de la agencia al contrato de concesión, para superar así las lagunas propias de un contrato atípico; en particular, como veremos, en materia de extinción contractual e indemnización por clientela.

Se trata de un contrato de duración, cuyo objeto consiste en promover la distribución de los productos del fabricante o proveedor mediante la reventa de los mismos. Se produce una integración económica entre concedente y concesionario, ya que este último, al revender los bienes del primero bajo su imagen de marca, se somete a las directrices comerciales establecidas por el concedente (precios recomendados, sistemas de financiación al comprador, servicio de atención postventa, seguimiento de campañas publicitarias y uso de signos distintivos, entre otros), quien se asegura de esta forma la distribución de sus productos con una imagen de mayor o menor prestigio (en función de la mayor o menor notoriedad de la marca y de las políticas de marketing seguidas emprendidas). El concedente mejora así la distribución de sus prestaciones sin asumir costes ni riesgos y en condiciones que contribuyen a prestigiar sus productos y servicios. Además, al facilitar la promoción y venta de sus productos o servicios a través de su red de concesionarios, racionaliza la producción y distribución pues aporta estabilidad al abastecimiento de la producción de sus productos principales, accesorios, repuestos, y demás, y fideliza además a la clientela mediante servicios de asistencia preventa y postventa. Por su parte, el concesionario se aprovecha de la clientela atraída por la marca del concedente para explotar su 
propia empresa de distribución, lo que no excluye que tenga que hacer una captación de clientela.

El contrato de concesión se caracteriza además por la existencia habitual de una doble exclusiva o exclusiva recíproca: una exclusiva de venta a favor del distribuidor, comprometiéndose el concedente a no vender sus productos a nadie más en la zona de influencia o territorio asignado al distribuidor; y una exclusiva a favor del proveedor por la que el concesionario se compromete a no distribuir productos de la competencia. Normalmente se pacta también en el contrato una cláusula de compra exclusiva a favor del concedente, comprometiéndose el concesionario a no comprar las mercancías objeto del contrato más que al concedente; aunque se admiten también (por imperativo del Derecho antitrust comunitario) los suministros cruzados entre miembros de la misma red, es decir, las compras entre concesionarios de distintos territorios integrados en la misma red del concedente.

La exclusiva territorial en beneficio del concesionario o distribuidor se consideraba tradicionalmente por la mayoría de la doctrina como un elemento esencial o consustancial al tipo contractual de la concesión mercantil; en concreto, se ha entendido que la exclusiva territorial evita posibles problemas al distribuidor en la captación de clientela, al garantizarle una posición de privilegio mediante un territorio acotado geográfica o demográficamente que le asegura una expectativa de ganancia que compensa el coste de entrada en la red de distribución y la dependencia o subordinación funcional respecto al concedente ${ }^{3}$. Sin embargo, la doctrina más moderna y renovadora, considera que la exclusiva territorial es un pacto natural pero no esencial en los contratos de concesión, pues la mera integración del distribuidor en la red del concedente le permite participar de las ventajas inherentes a un sistema de distribución con una demanda consolidada por el reclamo que supone la marca del principal, lo cual constituye per se una ventaja concurrencial ${ }^{4}$.

\section{Contenido del contrato. Derechos y obligaciones de las partes}

Por lo que se refiere al contenido del contrato, el concedente se compromete a suministrar sus productos de marca al concesionario en los términos pactados, obligándose, caso de pactar una exclusiva de venta a favor del distribuidor, a no vender esos mismos productos a otros comerciantes con establecimientos abiertos en

3 Cfr., Iglesias Prada, J.L., "Notas para el estudio del contrato de concesión mercantil", en AA.VV.,Estudios en Homenaje a R. Uría, Civitas, Madrid, 1978, p. 255; DOMÍNGUEZ GARCÍA, "Aproximación al régimen jurídico de los contratos de distribución. Especial referencia a la tutela del distribuidor”, cit., p. 427; Ma. T. PUENTE MUÑOZ, El contrato de concesión mercantil, cit., p. 427.

4 Martínez Sanz, F., "Contratos de distribución comercial: concesión y franchising”, Scientia Iuridica, 1995, p. 348; del mismo, Indemnización por clientela en los contratos de agencia y concesión, 2a edición, Civitas, Madrid, 1998, p. 318, nota 706; también MORALEJO MENÉNDEZ, El contrato mercantil de concesión, cit., pp. 118-119. El Tribunal Supremo español rechaza también la esencialidad de la exclusiva a favor del concesionario (Cfr., SSTS de 18 de diciembre de 1995, 20 de enero de 2000 ó 13 de diciembre de 2004). 
la misma zona geográfica del concesionario ${ }^{5}$.

$\mathrm{Si}$ el concedente es un fabricante ${ }^{6}$, responderá frente al concesionario de la falta de conformidad de sus productos con el contrato de compraventa, podrá ofrecer que los productos puestos a la venta vayan acompañados de una garantía comercial y deberá ofrecer garantía comercial en todo caso de sus productos (sin perjuicio de las garantías de consumo mínimas previstas con carácter imperativo en la Ley) y un adecuado servicio técnico, así como el suministro de piezas de repuesto durante un tiempo mínimo de cinco años a contar desde la fecha en que el producto deje de fabricarse ${ }^{7}$.

Finalmente, el concedente deberá apoyar al concesionario en su actividad de distribución, mediante campañas de formación, información puntual sobre los productos o servicios y demás, y permitirle el uso de sus derechos de propiedad industrial en los términos pactados en el contrato.

Por su parte, el concesionario asume como obligación principal la de promover diligentemente los productos y servicios del concedente (obligación genérica de carácter promocional); en particular la reventa de los productos de éste en el territorio de influencia asignado, lo que genera demanda y crea valor para la empresa del principal, lo cual revertirá, lógicamente, en su propia empresa de distribución. Tiene, por tanto, la obligación de comercializar los productos suministrados por el concedente; no obstante, ante la falta de concreción de esa obligación genérica, es habitual encontrar en los contratos de concesión pactos complementarios por los que el concesionario se obliga a adquirir periódicamente un número mínimo de productos del principal, a fin de mantener un stock mínimo en sus establecimientos (cláusula de cuota mínima, en productos principales y recambios) que garantice en todo momento el abastecimiento adecuado del mercado, y también pactos por los que se fijan objetivos mínimos de ventas, cuyo incumplimiento manifiesto y reiterado puede dar lugar a la resolución del contrato por el concedente ${ }^{8}$. La jurisprudencia

5 No es extraño, sin embargo, encontrar limitaciones de la exclusiva para permitir a otros miembros de la red vender en la misma zona (por ejemplo, zonas muy pobladas) o para que el concedente pueda vender directamente a determinados clientes (no revendedores) de esa misma zona (por ejemplo, grandes empresas que negocian directamente con el concedente y no con el concesionario de su zona ante la entidad del pedido realizado (que supera las posibilidades del concesionario).

6 En ocasiones, el concedente puede ser un importador exclusivo de productos de una marca extranjera en un determinado país, el cual se compromete con el fabricante a crear una red de distribuidores internos, por territorios en dicho país, asumiendo así la posición de "Master Franchise".

7 Cfr., en la legislación española, el Art. 12 de la Ley 7/1996, de 15 de enero, de Ordenación del Comercio Minorista, y los Arts. 114-127 del Texto Refundido de la Ley General para la Defensa de los Consumidores y Usuarios, aprobado por el Real Decreto Legislativo 1/2007 de noviembre.

8 Los tribunales suelen hacer interpretaciones restrictivas de este tipo de cláusulas, en un intento por proteger al distribuidor en cuanto parte débil del contrato frente a posibles abusos del concedente. Por eso, sólo se han estimado resoluciones unilaterales del contrato por parte del concedente, cuando se constate una diferencia evidente entre los resultados alcanzados por el concesionario y los mínimos pactados en el contrato. Cfr., Sentencia del Tribunal Supremo español de 8 de noviembre de 1995. 
española admite la validez de estas cláusulas de minimis fijadas unilateralmente por el concedente en materia de compras y ventas, salvo que resulten manifiestamente abusivas 9 .

Asimismo, en desarrollo de la obligación genérica de promoción de los productos del principal, el concesionario deberá seguir las directrices o instrucciones comerciales del concedente, ajustarse a sus campañas promocionales de venta, informarle regularmente de las operaciones efectuadas y, si así se pacta, de la clientela adquirida, así como prestar un servicio de asistencia postventa directamente o a través de terceros.

Es habitual también que el concesionario asuma una obligación de compra exclusiva al concedente, lo cual enlaza directamente con la obligación de no competir con las prestaciones del principal al comprar productos sustitutivos de competidores o actuar como agente o representante de prestaciones de la competencia ${ }^{10}$. Además, el concesionario deberá pagar el precio convenido en el contrato al adquirir las mercancías del principal, sin perjuicio de la existencia de descuentos, premios y otros. para fomentar la actividad del distribuidor. Finalmente, el concesionario deberá respetar los límites de la licencia de signos distintivos $\mathrm{y}$, en su caso, de patentes, diseños o know how; derechos de propiedad intelectual que constituyen parte importante, si no fundamental (en el caso del uso de la marca), de este tipo de contratos.

\section{Extinción del contrato: causas de resolución, indemnizaciones y stock sobrante}

Es de singular importancia en los contratos de concesión mercantil toda la problemática anudada a la duración y extinción del contrato. Los contratos pueden pactarse por tiempo determinado (normalmente con prórrogas automáticas por tácita reconducción, salvo denuncia del contrato por una de las partes) o indefinido. En este último caso, al tratarse -al igual que en la agencia comercial- de contratos de duración o tracto sucesivo basados en la confianza recíproca (intuitus personae/instrumentii),

9 Vid. Sentencia del Tribunal Supremo español de 2 de marzo de 2001.

10 Sin embargo, este tipo de cláusulas ya no son eficaces en el mercado europeo de los vehículos a motor, sobre todo en el campo de los repuestos o recambios, pues el Reglamento (CE) No. 1400/2002 de la Comisión, de 31 de julio de 2002, sobre acuerdos verticales en el sector de vehículos a motor, quiso fomentar la competencia al permitir expresamente los establecimientos o concesionarios y los talleres de reparaciones y mantenimiento multimarca. Este Reglamento ha sido sustituido por el vigente Reglamento (UE) No. 461/2010 de la Comisión, de 27 de mayo de 2010, relativo a la aplicación del artículo 101, apartado 3, del Tratado de Funcionamiento de la Unión Europea a determinadas categorías de acuerdos verticales y prácticas concertadas en el sector de los vehículos a motor, aunque mantiene en esencia el mismo régimen jurídico. Asimismo, no es raro encontrar pactos contractuales, por los que se permite a un concesionario abastecerse y adquirir los productos de marca del concedente a cualquier otro concesionario de la misma red. 
cualquiera de las partes podrá poner fin al contrato en cualquier momento (aunque no esté previsto en el contrato) mediante el oportuno preaviso ${ }^{11}$. Además pueden resolverse los contratos de concesión por las causas generales de extinción de los contratos, por las expresamente pactadas en el contrato y, particularmente, por el incumplimiento grave de las obligaciones contractuales. También amparándose, una vez más, en el carácter fiduciario del contrato, por la muerte, declaración de fallecimiento o extinción de la personalidad jurídica del concesionario o del concedente $^{12}$. Más complejo es lo relativo a la extinción por la declaración de concurso

11 Si existe un plazo de preaviso pactado expresamente y se incumple, la parte que resuelva deberá indemnizar los daños y perjuicios causados al otro (Cfr., Sentencia del Tribunal Supremo español de 30 de noviembre de 1999). El Tribunal Supremo español admite la resolución unilateral de contratos de concesión indefinidos, pero si se hace de mala fe o de forma manifiestamente abusiva, como sucedería por ejemplo con rupturas intempestivas o con plazos de preaviso objetivamente insuficientes, podría dar lugar a la oportuna indemnización de daños y perjuicios (Cfr., SSTS de 24 de marzo de 1993, 25 de enero de 1996 ó 22 de marzo y 16 de septiembre de 1998). Para solventar dudas en favor de la seguridad jurídica, doctrina científica y jurisprudencia sugieren la utilidad de recurrir a una aplicación analógica de las normas extinción del contrato y plazo de preaviso de la Ley de Contrato de Agencia española (Arts. 24-26), admitiendo el hecho de que agencia y contratos de distribución son instrumentos negociales funcionalmente análogos, tal y como se expuso anteriormente (Cfr., STS de 28 de enero de 2002). Vid. MORALEJO MENÉNDEZ, El contrato mercantil de concesión, cit., pp. 260 y ss.

12 Aunque habría que valorar la posibilidad de aplicación analógica del Art. 27 LCA, que prevé la extinción del contrato únicamente por la muerte o declaración de fallecimiento del agente (o por la extinción de la empresa social), pero no por la del empresario o agenciado siempre que se produzca la continuidad de la empresa por los herederos, sin perjuicio de la denuncia unilateral posterior $\mathrm{ad}$ nutum respetando los plazos de preaviso. Vid. VAQUERO PINTO, Ma. J., "La terminación de los contratos de distribución", cit., p. 322.

Como vimos antes para el contrato de agencia comercial (supra III.3), la doctrina discute que el contrato deba extinguirse automáticamente por la muerte o declaración de fallecimiento del agente, ya que la confianza (intuitus) entre agente y agenciado no reside en los aspectos personales, sino en los aspectos organizativos de su empresa, los cuales pueden ser mantenidos por los sucesores. Con mayor razón se puede aplicar este razonamiento al contrato de concesión comercial, ya que en este caso sí que es evidente que la confianza contractual propia de la relación duradera y estable reside en la adecuada estructura de la organización empresarial del concesionario revendedor, la cual puede ser mantenida por los herederos del concesionario fallecido. Además, en todo caso le queda al concedente la posibilidad de resolver unilateralmente y ad nutum el contrato. Naturalmente, no sucederá así en los casos de extinción de la empresa social (concesionario-persona jurídica), ya que la continuación del contrato será imposible por abandono absoluto de la actividad empresarial del concesionario; salvo, claro está, en los casos en que la extinción se deba a procesos de sucesión universal ínter vivos como la fusión, la escisión total o la cesión global de activo y pasivo a un tercero.

El fallecimiento del concedente no tiene realmente por qué erigirse en causa de extinción automática del contrato, pues el negocio puede seguir con los herederos. Ahora bien, si el concedente es una persona jurídica (como será habitual), su disolución y liquidación sí que conllevará la extinción del contrato de concesión por abandono total de la actividad, salvo que se deba a procesos de sucesión universal societarios como la fusión, la escisión total o la cesión global del activo y pasivo empresarial a terceros. 
de cualquiera de la partes, proponiendo la doctrina una interpretación analógica de lo dispuesto para el contrato de agencia en el Art. 26.1 b) LCA, según el cual -frente a la regla general de la legislación concursal (Art. 61 LC 2003) para la extinción de contratos bilaterales con obligaciones pendientes- cualquiera de las partes podrá dar por finalizado el contrato en cualquier momento, sin necesidad de preaviso, cuando la otra parte (concedente o concesionario) hubiera sido declarado en concurso ${ }^{13}$.

La extinción del contrato de concesión puede causar importantes daños y perjuicios al concesionario si no hubiera dispuesto de tiempo suficiente para amortizar las inversiones efectuadas en su empresa de distribución, por el lucro cesante consecuente con la extinción contractual, así como por los costes derivados de despidos; también puede causar desequilibrios patrimoniales próximos al enriquecimiento injusto al aprovecharse el concedente del fondo de comercio (cartera de clientes) creado por el concesionario. Por eso, -al igual que en la agencia comercial- en la extinción de este contrato tiene una especial importancia el capítulo de indemnizaciones al concesionario $^{14}$.

En este sentido, tras la aprobación de la Ley 12/1992, de 27 de mayo, de Contrato de Agencia, en España existen opiniones contradictorias sobre la oportunidad y conveniencia de aplicar analógicamente al contrato de concesión la regulación que en materia de indemnizaciones por extinción contractual prevé expresamente la legislación sobre el contrato de agencia: en concreto, la indemnización por daños y perjuicios (Art. 29 LCA) y, sobre todo, la indemnización por clientela (Art. 28 LCA $)^{15}$.

En relación con la indemnización por daños y perjuicios derivados -para el concesionario- de una resolución unilateral e intempestiva del contrato por parte del concedente, aunque algún sector doctrina y jurisprudencial reconoce la posibilidad de aplicar analógicamente el Art. $29 \mathrm{LCA}^{16}$, por lo general, las inversiones no

13 Vid. Ávila de La Torre, A., "Consideraciones generales en torno al concurso en los contratos de distribución”, en Herrero García, Mª J. (Dir.), La Contratación en el Sector de la Distribución Comercial, Thomson-Reuters Aranzadi, Navarra, 2010, pgs. 351 y ss.

14 A pesar de no tener reconocimiento legal en el Código de Comercio, e incluso antes de la aprobación de la Ley de Contrato de Agencia de 27 de mayo de 1992, la jurisprudencia española vino reconociendo indemnizaciones por daños y por clientela en contratos de agencia y de distribución (fundamentalmente de concesión comercial), invocando principios generales del derecho como la buena fe o el enriquecimiento injusto. Cfr., Sentencias del Tribunal Supremo español de 17 de octubre de 1995, 22 de marzo de 1988 y 16 de febrero de 1990.

15 En un ámbito más genérico, el art. 34 de la Ley 29/1994, de 24 de noviembre, de arrendamientos urbanos (LAU), recoge el derecho del arrendatario de locales de negocio a ser indemnizado cuando, deseando continuar con el arrendamiento, deba abandonar el local por transcurso del plazo contractual, siempre y cuando de alguna manera el arrendador o un nuevo arrendatario se pueda beneficiar de la clientela obtenida por el antiguo arrendatario.

16 Así, Martínez Sanz, F., "En torno a las consecuencias patrimoniales de la extinción del contrato de distribución comercial. (A propósito de la STS, Sala 1, de 27 de mayo de 1993", Cuadernos de Derecho y Comercio, 1993, pp. 217 y ss. Sentencia del Tribunal Supremo español de 23 de enero de 2007. 
amortizadas por el concesionario (gastos de confianza) por un desistimiento unilateral del contrato por el concedente suelen reclamarse por una acción ordinaria de daños y perjuicios contractuales y alegar el abuso de derecho y la mala fe en el ejercicio del desistimiento unilateral. Se entiende así, con carácter dominante, que el desistimiento unilateral del contrato puede considerarse intempestivo y de mala fe cuando el contrato no ha alcanzado la duración esperada por una de las partes para amortizar los gastos de explotación y alcanzar unas expectativas razonables de ganancia ${ }^{17}$. Por eso, cuando una relación contractual ha sido lo suficientemente prolongada en el tiempo, el Tribunal Supremo ha entendido que ha habido tiempo suficiente para amortizar inversiones y cumplir razonablemente las expectativas de ganancias, se descarta así una indemnización por daños y perjuicios derivados de la resolución unilateral del contrato por el concedente ${ }^{18}$.

Por lo que se refiere a la indemnización por clientela en la extinción del contrato de concesión, la cuestión de fondo reside en determinar si el distribuidor ha contribuido eficazmente a incrementar y fidelizar (conservar) con su actuación la cartera de clientes en beneficio propio y del concedente, o bien si el concesionario disfruta desde el principio de una clientela ajena, asociada exclusiva o principalmente a la atracción o reclamo comercial que ejerce el signo distintivo del concedente.

Como se ha dicho ya, en España se ha discutido intensamente desde hace años sobre la posible aplicación analógica del Art. 28 LCA a la extinción de los contratos de concesión comercial. Doctrina y jurisprudencia españolas mantienen posturas antagónicas al respecto ${ }^{19}$. En realidad, no parece posible una solución unívoca, sino

17 Vid. Vaquero Pinto, Ma. J., “La terminación de los contratos de distribución”, cit., pp. 336-338.

18 Cfr., STS de 26 de abril de 2004.

19 A favor de la aplicación analógica de la indemnización por clientela prevista para la agencia al contrato de concesión, al considerar que la clientela constituye un activo común del concedente y el concesionario, se manifiestan, entre otros, MARTÍNEZ SANZ, F., La indemnización por clientela en los contratos de agencia y concesión, cit., pp. 97 y ss.; y MORALEJO MENÉNDEZ, I., El Contrato mercantil de concesión, cit., pp. 315 y ss.; también las Sentencias del Tribunal Supremo español de 12 de junio de 1999, 10 de marzo y 1 de abril de 2000, 21 de noviembre de 2005, 20 de julio de 2007 ó 15 de enero de 2008, entre otras.

En contra de esa aplicación analógica, poniendo de manifiesto el distinto sistema de retribución del agente (comisiones sobre operaciones concluidas por el principal con su intervención) y el concesionario (margen de reventa de los productos del fabricante), se pronuncia el profesor PAZARES, C., "La indemnización por clientela en el contrato de concesión", en AA.VV., Estudios Jurídicos en Homenaje al profesor Justino Duque, T. II, Universidad de Valladolid, Valladolid, 1998, pp. 1287 y ss.; también las Sentencias del Tribunal Supremo español de 16 y 17 de octubre de 1995, 20 de enero y 12 de julio de 2000 ó 27 de octubre de 2005, entre otras.

Para una exposición completa sobre la evolución de la jurisprudencia española, vid. Díaz Echegaray, J.L., "El contrato de distribución exclusiva o de concesión", en Bercovitz Rodríguez-Cano, A. / Calzada Conde, Ma. A., Contratos Mercantiles, T. I, Thomson-Reuters Aranzadi, Navarra, 2009, pp. 791 y ss.; y también, Vaquero Pinto, Ma. J., "La terminación de los contratos de distribución", cit., pp. 336 y ss. 
que habrá que estar al caso concreto para apreciar todos los elementos concurrentes y decidir si ha tenido más peso en la formación del fondo de comercio (cartera de clientes) la actividad del concesionario o el reclamo de la marca del concedente, lo cual dependerá del tipo de productos de que se trate, de la estructura del mercado y de la mayor o menor notoriedad de la marca.

Puede decirse, no obstante que, con carácter general, la mayoría de la doctrina española entiende que en la concesión, como en la agencia, al extinguirse el contrato existe en vía de principio un activo común entre el principal o proveedor y el distribuidor que no es otro que la clientela captada durante la vigencia del contrato. Esa captación puede tener lugar en parte por la fuerza atractiva de la marca o signo distintivo del proveedor y en parte por la labor activa del distribuidor en la búsqueda y fidelización de clientela. El Tribunal Supremo español tiene declarado, en este sentido, que la clientela supone una realidad económica que debe resarcirse por quien se aproveche de su aporte, y se integra por lo aportado y dejado en la esfera de desenvolvimiento del concesionario o agente que va seguida de un disfrute por parte del empresario con la consiguiente pérdida que su desaparición supone para el agente o distribuidor ${ }^{20}$. Sin embargo, una compensación equitativa para el distribuidor sólo tiene sentido cuando dicha clientela sea captada directamente por el propio agente o distribuidor o cuando haya colaborado en la creación y consolidación de la misma, beneficiándose posteriormente de la misma el proveedor o principal, de modo que no procederá indemnización alguna cuando el distribuidor o agente no sólo no haya contribuido en la generación de clientela, sino que incluso, con su actuación, haya dado lugar a la pérdida de parte de la clientela existente ${ }^{21}$.

En definitiva, frente a posiciones ancladas en el análisis económico del derecho, según las cuales reconocer una indemnización por clientela al distribuidor haría perder elasticidad al aparato distributivo a partir del hecho de que, éste, en su condición de empresario independiente, debe quedar sometido al libre juego de la contratación y valorar los riesgos asumidos al concluir el contrato, puede decirse que, de manera dominante, doctrina y jurisprudencia española admiten como regla general o punto de partida, por razones de equidad basadas en la - a priori-posición de debilidad del concesionario o distribuidor frente al concedente o proveedor (que, por lo general, tratará de imponer un contrato-tipo a todos los miembros de su red), la posibilidad de que el concesionario reclame una indemnización al concedente al tiempo de la extinción del contrato de concesión comercial, pues queda reducido todo en la práctica a un difícil problema de prueba sobre la intervención del concesionario o distribuidor en la captación y mantenimiento de clientela y en el aprovechamiento de la misma por el concedente tras la finalización del contrato ${ }^{22}$.

20 SSTS de 26 de julio de 2000, 3 de mayo de 2002, 23 de diciembre de 2002 y 9 de febrero de 2006.

21 Cfr., STS de 5 de febrero de 2004.

22 Vid. Díaz Echegaray, "El contrato de distribución exclusiva o de concesión”, cit., pp. 800 y ss. 
Naturalmente, de admitirse la aplicación analógica del Art. 28 LCA, habrá que estar a los factores o elementos determinantes de esa indemnización allí previstos ${ }^{23}$. Así, tendrá que producirse la extinción del contrato por causas no imputables al distribuidor, será preciso demostrar que el distribuidor ha aportado nuevos clientes o incrementado sensiblemente las operaciones de la clientela anterior y, finalmente, acreditar que su actividad anterior pueda producir ventajas sustanciales al concedente. Con lo cual, no se admite la indemnización por clientela si no se prueba que el concedente ha seguido sirviéndose de la clientela del concesionario para distribuir sus productos entre la misma ${ }^{24}$, cuando desciende el volumen de negocios ${ }^{25} \mathrm{O}$ cuando sólo se acredite un mantenimiento de clientela pero no un incremento sensible de la misma ${ }^{26}$. Asimismo, como factores de equidad para estimar o no una acción de indemnización por clientela $\mathrm{y}$, en tal caso, cuantificar la indemnización pertinente, se tienen en cuenta, por ejemplo, la existencia o no de un pacto de exclusiva ${ }^{27}$, el mayor o menor prestigio de la marca del concedente como elemento de atracción de clientela en función de los sectores de actividad ${ }^{28}$ y el margen de beneficio del distribuidor (fundamental para la cuantificación de la indemnización).

En la República de Colombia, el concepto amplísimo o multifuncional de agencia previsto en el Art. 1317 del Código de Comercio, serviría para aplicar las indemnizaciones previstas en el Art. 1324 del mismo Código para la terminación del contrato, tanto a los casos de agencia en sentido estricto, como a los casos de agencia en sentido amplio (concesión e incluso franquicia) ${ }^{29}$, ya que se prevé la aplicación automática de las indemnizaciones al margen de cualquier demostración sobre la captación real o no de clientela para el principal.

Estas indemnizaciones por daños y por clientela han sido objeto de acaloradas discusiones durante muchos años, ya que su aparente aplicación cogente o automática supone una importante barrera para la utilización de la institución de la agencia y de los contratos de distribución exclusiva en el país. Esto ha motivado que no se haya planteado en toda su dimensión la posible aplicación de estas indemnizaciones a la extinción de contratos de distribución exclusiva o concesión.

23 Así se pronuncia expresamente el Tribunal Supremo español en sus Sentencias de 13 de febrero y 4 de marzo de 2009.

$24 \quad$ STS de 10 de febrero de 2004

25 STS de 20 de mayo de 2004.

26 STS de 28 de enero de 2002

27 STS de 29 de septiembre de 2006

28 Así, en el sector de los automóviles, se tiene muy presente la fama de la marca del concedente como instrumento de atracción de compradores, para negar la indemnización o para reducir la cuantía de la misma. Cfr., SSTS de 26 de junio de 2003, 20 de julio de 2007, 3 de marzo de 2008 ó 21 de enero de 2009. Vid. el comentario de Sacristán Bergia, F., "Resolución del contrato de concesionario de automóviles y derecho a la indemnización por clientela", Revista de Derecho de la Competencia y la Distribución, La Ley, No. 2, 2008, pp. 275 y ss.

29 Vid. supra, III.4. 
Como decimos, el tenor literal del Art. 1317 Ccom. sugiere un concepto amplio y multifuncional de agencia que abarcaría por igual la agencia en sentido estricto y los contratos de distribución (en particular la concesión comercial), lo cual justificaría la aplicación de las indemnizaciones a todos ellos. Sin embargo, como se expuso anteriormente, la jurisprudencia de la Corte Suprema de Colombia y buena parte de la doctrina restringen la definición del Art. 1317 Ccom al genuino contrato de agencia, por el que un empresario independiente promociona el negocio de un tercero por cuenta y nombre ajenos, sin asumir el riesgo de la operación, pues deja fuera del precepto legal (contrato atípico) a los contratos de distribución en el que un intermediario fabrica o revende los productos de un tercero por cuenta y en interés propio al asumir el riesgo de las operaciones. De manera, entonces, que las indemnizaciones del Art. 1324 Ccom se aplicarían solamente a los contratos de agencia stricto sensu, aunque, atende a la proximidad funcional de ambos contratos y al propio tenor literal de la definición de agencia en el Código de comercio colombiano, podría valorarse la posibilidad de una aplicación analógica de lo dispuesto fundamentalmente para el genuino contrato de agencia comercial a los contratos de distribución o concesión comercial.

Por último, merece destacarse en este capítulo de la extinción del contrato de concesión o distribución (generalmente) exclusiva, el problema de los stocks sobrantes: productos y piezas de recambio en poder del distribuidor al tiempo de producirse la extinción del contrato ${ }^{30}$. Problema relacionado normalmente con la cláusula contractual de cuota mínima, que obliga al distribuidor a adquirir y mantener un mínimo de unidades de productos y recambios para mantener abastecido suficientemente el mercado y atender inmediatamente los pedidos de los clientes. Se entiende generalmente que el distribuidor podrá vender los productos y recambios sobrantes libremente, aunque al margen de la cobertura del proveedor o concedente ${ }^{31}$. Sucede, sin embargo, que puede resultar complicada la comercialización de los productos de la marca del concedente sin la cobertura de éste último proporcionada por el contrato de concesión comercial ya extinto; y más aún si se hubiera estipulado una prohibición post contractual por parte del concesionario. Por eso, la solución práctica reside en la introducción en el contrato de cláusulas por las que el proveedor concedente asuma la obligación de recompra del stock sobrante al tiempo de producirse la extinción del contrato a un precio razonable (al menos de los productos

30 Vid. con detalle, en Díaz Echegaray, "El contrato de distribución exclusiva o de concesión”, cit., pp. 798 y ss.; y en Vaquero Pinto, Ma. J., "La terminación de los contratos de distribución”, cit., pp. 347 y ss.

31 En materia de marcas -como veremos en la segunda parte de este trabajo- dado que el concesionario compra productos del proveedor para revenderlos, con esa primera adquisición se produce el agotamiento del derecho de marca liberando así la posterior reventa de esos productos incluso una vez extinto el contrato de concesión. Aunque, eso sí, el otrora distribuidor no podrá hacer un uso proactivo de la marca del concedente, limitándose a un uso descriptivo del signo para identificar los productos que pone a la venta. 
y recambios cuya adquisición por el concesionario estuviera motivada por cláusulas de cuota mínima) que sería el precio del suministro y no el precio de reventa en el mercado, o bien, cláusulas que autoricen expresamente al concesionario a proceder a la reventa de ese stock en un plazo prudencial tras la extinción del contrato.

A falta de pacto contractual, las soluciones dependerán de las circunstancias del caso concreto. Así, en los contratados de concesión de duración determinada se entiende que el distribuidor debe asumir el riesgo empresarial de la no reventa de los productos y recambios adquiridos del proveedor concedente o de otros miembros de la red de distribución. En los contratos de duración indefinida se entiende que si el plazo de preaviso es suficiente para liquidar razonablemente el stock, deberá asumir el concesionario el riesgo de la falta de venta; como también deberá asumirlo si la resolución unilateral del contrato por el concedente se debe a un incumplimiento contractual del concesionario ${ }^{32}$. $\mathrm{Si}$, por el contrario, en contratos de duración de duración indefinida se resuelven por incumplimiento del proveedor o éste no respeta el plazo de preaviso pactado o realiza una preaviso intempestivo contrario a los postulados de la buena fe contractual, se considera que el valor del stock sobrante se debe incluir en la cuantía de la reclamación indemnizatoria por daños y perjuicios del concesionario (no a precio de mercado, sino al precio del suministro), si bien con la obligación de restituir ese stock al proveedor para evitar situaciones de enriquecimiento injusto del distribuidor ${ }^{33}$.

\section{EL CONTRATO DE DISTRIBUCIÓN SELECTIVA}

\section{Concepto y caracteres esenciales del contrato}

Dentro del marco de la distribución indirecta integrada, los sistemas de distribución selectiva o autorizada (conocidos también, por influencia francesa, como sistemas de "agrèation") se caracterizan por una selección previa de distribuidores mayoristas y minoristas por parte del proveedor (que puede ser el propio fabricante, o bien una filial de éste en otro país o un importador exclusivo que siguen las instrucciones del fabricante para crear una red de distribuidores autorizados), basada en criterios objetivos específicos (generalmente de carácter cualitativo, tales como la cualificación profesional del revendedor y de su personal, así como la ubicación, dimensiones o imagen comercial de sus instalaciones), otorgándoles un trato preferencial en la adquisición de sus prestaciones así como asistencia técnica y para la formación, con la finalidad de que tales distribuidores autorizados

$32 \quad$ STS de 1 de febrero de 2001.

33 SSTS de 12 de diciembre de 1990, 12 de junio de 1999, 2 de diciembre de 2005 ó 3 de marzo de 2008. 
comercialicen por su cuenta y riesgo en sus establecimientos los productos o servicios de la marca objeto del contrato, en régimen de no exclusividad, con las directrices comerciales establecidas por el proveedor, prestar además, servicios de asistencia preventa (información) y postventa (reclamaciones, mantenimiento, reparaciones) a la clientela, y asume el compromiso de no revender los productos o servicios del proveedor a otros distribuidores -mayoristas o minoristas- no integrados en la misma red de distribución autorizada ${ }^{34}$.

Se trata de una modalidad contractual utilizada habitualmente en sectores muy concretos (perfumes y cosméticos, relojes, joyas y bisutería, alta tecnología, algunos automóviles o motocicletas, productos de lujo, en general), en los que importa más la política de prestigio de la marca que la política de precios, pues se trata de llegar a un público que busca productos rodeados de una aureola de reputación o renombre. Es un sistema de distribución que se basa en la selección de revendedores cualificados por parte del proveedor (fabricante o importador), con la finalidad de que procedan a la promoción de los productos del fabricante mediante su reventa en los establecimientos del distribuidor, se salvaguarda el prestigio o reputación de la marca y se cuida la atención al cliente mediante una asistencia preventa y postventa.

Es un contrato atípico, reconocido no obstante con carácter expreso en la jurisprudencia y normativa comunitaria sobre acuerdos verticales ${ }^{35}$, en el que se apuntan como caracteres básicos: a) el compromiso del proveedor de vender los bienes o servicios objeto del contrato directa o indirectamente (a través de mayoristas) sólo a distribuidores seleccionados sobre la base de criterios específicos, por lo general -pero no necesariamente- de carácter o naturaleza cualitativa ${ }^{36}$; y b) el

34 Sobre el concepto y caracteres de la distribución selectiva, vid. Font Ribas, A., Mercado común y distribución: la distribución exclusiva y selectiva a través de representantes y concesionarios, Bosch, Barcelona, 1987, pp. 23 y ss.; también, Giner Parreño, C.A., Distribución y Libre Competencia (El aprovisionamiento del distribuidor), Montecorvo, Madrid, 1994, pp. 68-69 y 440 y ss.; Górriz López, C., Distribución Selectiva y Comercio Paralelo, Thomson-Civitas, Madrid, 2007, pp. 31 y ss.; Carbajo Cascón, F., "El contrato de distribución selectiva", en Bercovitz Rodríguez-Cano, A./Calzada Conde, Ma. A., (Dir.), Contratos Mercantiles, Thomson-Reuters Aranzadi, Madrid, 2009, pp. 816 y ss.; del mismo autor, La distribución selectiva y el comercio paralelo de productos de lujo, Ibáñez-De Palma-Universidad Javeriana de Bogotá, Santa Fe de Bogotá, 2009, pp. 46 y ss.; también, VAQUERO PINTO, Ma. J., "Contrato de distribución autorizada o selectiva", en Bercovitz Rodríguez-Cano, R., (Dir.), Tratado de Contratos, Vol. III, Tirant lo blanch, Valencia, 2009, pp. 3190 y ss.

35 Cfr., Sentencia del Tribunal de Justicia de las Comunidades Europeas de 25 de octubre de 1977 (As. 26/76, Metro I. Cfr., Art. 1 d) del Reglamento (CE) 2790/1999 sobre acuerdos verticales, sustituido por el Reglamento (UE) 330/2010 sobre acuerdos verticales, que reproduce la normativa anterior. Puede decirse, así, que las disposiciones sobre competencia sirven como instrumento de integración del contrato de distribución selectiva, al igual que con el resto de los contratos de distribución indirecta integrada (concesión y franquicia).

36 Tradicionalmente, tanto la jurisprudencia del Tribunal de Justicia de las Comunidades Europeas como la mayoría de la doctrina científica consideraba que los criterios de selección deben ser de naturaleza cualitativa para su aplicación objetiva y uniforme, niegan, por tanto, la validez de 
compromiso de los distribuidores agregados de promocionar activamente la venta de esos productos, mediante la publicidad y prestar servicios de atención a la clientela antes y después de la venta, así como el compromiso de no vender esos productos o servicios de marca a distribuidores o agentes no autorizados, es decir, no incluidos en la red de distribución creada por el proveedor ("free riders" o comerciantes paralelos, ajenos a la red), para eliminar así la competencia intramarca fuera de la red ${ }^{37}$.

criterios de selección cuantitativa que limiten el número de distribuidores autorizados por territorio. Vid. Giner Parreño, Distribución y Libre Competencia, cit., p. 447, con cita de Jurisprudencia. Criterios cualitativos relativos a las dimensiones, ubicación o reputación del establecimiento comercial donde se quieren vender los productos, las posibilidades de contribución a la publicidad comercial del producto por el distribuidor, la existencia de personal especializado y/o de políticas de formación de personal cualificado, el compromiso de asistencia preventa (información) y posventa (mantenimiento, reparación, atención al cliente).

No obstante, otros autores admitían los criterios de selección cuantitativos, posiblemente pensaban en los acuerdos de distribución selectiva con comerciantes mayoristas a los que se otorgan zonas de exclusiva territorial, prohibiendo las ventas directas a usuarios finales y las ventas activas de los productos de marca en territorios reservados a otros distribuidores autorizados. Vid. Górriz López, Distribución selectiva y comercio paralelo, cit., pp. 207-208.

La polémica fue zanjada por el Reglamento (CE) No. 2790/99, sustituido recientemente por el Reglamento (UE) No. 330/2010 sobre acuerdos verticales, los cuales (Cfr., art. 1 e.) no establecen restricción alguna respecto a los bienes o servicios que pueden ser objeto del sistema de distribución selectiva (abriéndolo así a todo tipo de productos, sean o no de lujo en sentido estricto), ni tampoco respecto a la naturaleza de los criterios de selección, limitándose a decir que el proveedor podrá seleccionar distribuidores sobre la base de "criterios específicos"; de modo que tales criterios ya no tendrán que ser exclusivamente cualitativos relacionados con la naturaleza de los bienes o servicios, pudiendo el proveedor introducir también criterios cuantitativos de acuerdo con sus intereses empresariales y, por tanto, criterios discriminatorios en el acceso al mercado de la distribución de sus productos. Vid. ampliamente en Carbajo Cascón, F., "El contrato de distribución selectiva", cit., pp. 831 y ss. La objetividad de los criterios cualitativos de selección, supone que el comerciante no puede negar la integración en la red de distribución a aquellos distribuidores que así lo deseen siempre que cumplan escrupulosamente con los requisitos objetivos, pues de lo contrario -más allá de un margen razonable de discrecionalidad para el principal- estaría utilizando los criterios de selección cualitativos para introducir fraudulentamente criterios de selección cuantitativos. Sin embargo, la posible combinación de esos criterios cualitativos con criterios cuantitativos permitirá al proveedor establecer restricciones al número de distribuidores en un territorio, discriminando así el acceso a la red de distribución. Ello dependerá de si el distribuidor autorizado es un mayorista o almacenista y también de la propia naturaleza y prestigio de los productos objeto de comercialización mediante estos sistemas de distribución, en el entendimiento de que a mayor notoriedad o renombre puede resultar necesario restringir los puntos de comercialización para preservar la aureola de prestigio frente al público demandante.

37 El fabricante compite en el mercado no en base al precio, sino a la calidad y prestigio de los productos ofertados. El conjunto del sistema de distribución selectiva gira en torno a la imagen de prestigio de la marca, por lo que el proveedor o principal quiere mantener ese halo de reputación y controlar la comercialización que de los productos hacen los distribuidores; razón por la que se prohíbe expresamente a los distribuidores autorizados la venta o suministro de esos productos a comerciantes mayoristas o minoristas que no pertenezcan a la red de distribución selectiva. Obviamente, como veremos en el segundo trabajo de esta serie, este tipo de pactos supone una limitación a la libre competencia en el mercado; en concreto a la libre circulación de mercancías. 
Se trata, por tanto, de un sistema de distribución preferencial y restringido, pero no exclusivo, de productos de prestigio identificados por una marca notoria o renombrada: los distribuidores autorizados podrán vender cualesquiera otros productos, incluidos aquellos que estén en competencia directa con los de la marca del proveedor del sistema de distribución selectiva, pero no podrán vender los productos objeto del contrato de distribución autorizada a comerciantes ajenos a la red $^{38}$.

Parece obvio, entonces, que el distribuidor autorizado goza de mayor autonomía organizativa y funcional que el concesionario. El grado de integración vertical es muy inferior. Solamente deberá presentar los productos del proveedor en la forma indicada por éste, prestando especial atención a la información al cliente, a la asistencia posventa y al cuidado de la imagen de la marca.

Por lo demás, como el resto de los contratos de distribución indirecta integrada, se trata de un contrato mercantil (celebrado entre empresarios independientes), consensual, bilateral y sinalagmático, oneroso y conmutativo, que generalmente se presenta como un contrato-tipo o contrato de adhesión predispuesto unilateralmente por el proveedor. Actúa, además, como un contrato-marco, pues sirve como esquema básico de organización de las relaciones jurídicas complejas continuadas, que recoge los derechos y obligaciones de las partes, el grado de integración empresarial y los actos singulares de ejecución del contrato. Se trata, en todo caso, de un contrato de duración o de tracto sucesivo, dado que la satisfacción de los intereses de las partes depende directamente de la prolongación y estabilidad de la relación negocial. Y, por último, es un contrato basado en la confianza recíproca entre las partes, aunque no tanto en las características personales (intuitus personae) cuanto en la estructura de su organización empresarial (intuitus instrumentii) $)^{39}$.

Sin embargo, se trata de acuerdos exentos por contribuir a la racionalización del mercado de la distribución en productos que se caracterizan por su calidad, prestigio, u otro, se beneficia también a los consumidores que buscan esos productos y una asistencia especializada antes y después de la venta (Cfr., Art. 4 b. iii, del Reglamento CE 2790/99 y Art. 4 b. iii, del Reglamento UE 330/2010). En definitiva, las autoridades europeas y nacionales de defensa de la competencia, parten de la premisa de que las restricciones en la competencia intramarca ("intrabrand competition") se compensan con la promoción de la competencia intermarca ("interbrand competition").

38 Esta prohibición constituye la característica esencial de los contratos y sistemas de distribución selectiva y su violación, permitiendo que comerciantes no autorizados vendan los productos de la red, puede acabar por viciar todo el sistema, que reduce drásticamente el prestigio o reputación de la marca en perjuicio del fabricante y de los miembros de la red de distribución. Por eso, la venta de productos de una red de distribución selectiva por un "free rider" (comercio paralelo) puede ser combatida por la vía de la competencia desleal (aprovecharse de una infracción contractual, engaño a los consumidores) o, según los casos, ejerciendo acciones por violación del derecho exclusiva de marca, como veremos en la segunda parte de este trabajo. Sobre esta problemática, véase Carbajo Cascón, F., La distribución selectiva y el comercio paralelo de productos de lujo, cit., con referencias de Derecho español y colombiano.

39 Vid. Carbajo Cascón, F., "El contrato de distribución selectiva", cit., pp. 822-823. 


\section{Contenido del contrato. Derechos y obligaciones de las partes}

Ante el carácter atípico del contrato de distribución selectiva y el escaso tratamiento jurisprudencial recibido hasta el momento, resulta fundamental para la determinación del contenido del contrato la normativa de libre competencia sobre acuerdos verticales que declara la licitud o ilicitud de algunas de las cláusulas contractuales habituales en este campo ${ }^{40}$.

En el contenido del contrato destaca la obligación del principal o proveedor de suministrar de forma regular los productos de marca e información sobre la misma al distribuidor oficial o autorizado, se excluye el suministro de esos mismos productos a distribuidores ajenos a la red de distribución.

Además, el proveedor debe proporcionar un trato uniforme a todos los miembros de la red, suministrar los productos ( $\mathrm{y}$, en su caso, los recambios, repuestos o accesorios del productos principal) objeto del contrato en función de la demanda del distribuidor; sin perjuicio del posible pacto de cláusulas de consumo mínimo que obligan al distribuidor a mantener un stock suficiente para abastecer la demanda del público y permiten al fabricante racionalizar su producción al calcular de antemano el mínimo de unidades de producción anual.

Asimismo, según la naturaleza de los productos objeto del contrato (v. gr., productos de alta tecnología), el proveedor suele comprometerse a proporcionar formación y capacitación profesional a los empleados del distribuidor autorizado, y a suministrar documentación técnica y prestar asistencia técnica al distribuidor cuando éste lo requiera. Por último, es importante también la obligación de suministrar al distribuidor material publicitario para la exposición de los productos objeto del contrato en los puntos de venta autorizados, en la línea de la publicidad general realizada por el proveedor para todos sus productos.

Por su parte, el distribuidor autorizado se compromete a adquirir los productos del proveedor en las condiciones estipuladas en el contrato (que pueden y suelen incluir cláusulas de adquisición o consumo mínimo), beneficiándose de las políticas de descuento fijadas por el proveedor; sin perjuicio de la posibilidad, ya comentada, de aprovisionarse de los mismos productos por medio de otros distribuidores autorizados integrados en la misma red de distribución del fabricante o proveedor (suministros cruzados). El distribuidor se compromete en todo caso a no adquirir esos mismos productos a terceros distribuidores ajenos al proveedor y a la red de distribuidores autorizados.

Se compromete además el distribuidor autorizado a presentar de manera permanente y claramente visible en sus establecimientos los productos de la marca del proveedor, confiriéndoles un trato privilegiado respecto a los productos de la

40 Cfr., Arts. 4 b, iii); 4 c) y 4 d) del Reglamento (UE) 330/2010 sobre acuerdos verticales. Sobre el contenido del contrato de distribución selectiva, vid. in extenso, CARBAJO CASCÓN, F., "El contrato de distribución selectiva", cit., pp. 846-858. 
competencia mediante lugares preferentes en escaparates y expositores (o en el la publicidad que se ofrezca en el sitio Web del distribuidor). En la misma línea, constituye una obligación habitual la de mantener un stock adecuado para abastecer la demanda así como la de ir renovando el stock a medida que vaya mejorándose la calidad o presentación de los productos del proveedor; obligaciones estas que se hacen extensivas a los recambios y accesorios y a los materiales de muestra (importantes en el sector de perfumes y cosméticos) de los productos finales.

Pero, sin duda, la obligación más característica de los distribuidores autorizados consiste en el compromiso de no vender los productos objeto del contrato a distribuidores paralelos que se sitúen al margen del sistema de distribución autorizada. Esto es, los distribuidores autorizados podrán vender los productos objeto del contrato de distribución selectiva a consumidores finales y a otros miembros de la misma red de distribución (suministros cruzados), pero en ningún caso podrán revender los productos objeto del contrato a otros comerciantes ("free riders") no integrados en la misma.

Es fundamental también el capítulo de obligaciones del distribuidor relacionadas con la asistencia al cliente antes y después de la venta. El distribuidor se compromete así contractualmente a mantener personal especializado en el servicio, consejo y demostración, adecuado a las características y número de los productos objeto del contrato, así como a ofrecer al cliente servicios de información postventa, mantenimiento y reparación cuando así lo exijan las características de los productos, incluido un servicio de tramitación de quejas, reclamaciones y devoluciones por el mal estado de los productos o por su falta de conformidad con el contrato (garantías de bienes de consumo y garantías comerciales ofrecidas voluntariamente por el proveedor).

Por lo demás, el contrato de distribución selectiva impone generalmente restricciones relativas al punto o puntos de venta autorizados para realizar la reventa de los productos objeto del sistema de distribución selectiva. Así, el distribuidor sólo podrá comercializar los productos objeto del contrato en los establecimientos abiertos al público expresamente autorizados por el proveedor en el contrato, con lo cual éste podrá controlar que la reventa de sus productos se haga según los criterios cualitativos establecidos para toda la red sobre ubicación, dimensiones y presentación de esos establecimientos a fin de mantener e incrementar el prestigio de su marca. Sin embargo, estas restricciones no pueden impedir a los distribuidores autorizados comercializar esos mismos productos a través de su propios Website en Internet (pues una restricción de esa naturaleza sería contraria al principio de libertad de empresa o libre iniciativa económica en un sistema de libre competencia); aunque el proveedor podrá exigir en el contrato que el sitio Web del distribuidor autorizado cumpla con una serie de condiciones idóneas para preservar en todo caso la sensación de lujo y prestigio de sus productos y garantizar además la asistencia al cliente. 


\section{Extinción del contrato}

El contrato de distribución selectiva se puede extinguir ${ }^{41}$ por el transcurso del plazo establecido en el mismo, salvo en los casos en que se prevean prórrogas expresa o tácitamente mediante el seguimiento en la ejecución de las respectivas prestaciones por ambas partes, en cuyo caso se prorrogará por tácita reconducción. En contratos de duración indefinida, podrá extinguirse por el mutuo acuerdo de las partes o por desistimiento unilateral de cualquiera de ellas sin necesidad de que concurra justa causa (resolutio ad nutum), al tratarse de un contrato basado en la confianza personal o empresarial (intuitus personae/ instrumentii), mediante un plazo razonable de preaviso, que, a falta de pacto, puede ser de un mes en contratos de corta duración (por analogía con lo dispuesto para el mandato mercantil en el Art. 302 del Código de Comercio español) o de un mes por cada año de contrato con un máximo de seis meses en los de larga duración (por analogía con lo dispuesto para la agencia comercial en el Art. 25.2 LCA).

También podrá extinguirse el contrato de distribución selectiva por la muerte, declaración de fallecimiento de cualquiera de las partes sin sucesión. También por la completa extinción de la persona jurídica (sea el proveedor o el distribuidor autorizado) sin haber cedido a terceros el negocio (fusión, escisión total, cuota de liquidación de sociedades de capital o cesión global de activo y pasivo).

La declaración de concurso del proveedor o del distribuidor no es causa de extinción automática de la relación contractual, sino que, en principio, quedará sometida a lo dispuesto con carácter general para las relaciones contractuales bilaterales con obligaciones recíprocas pendientes en el Art. 61 de la Ley 22/ 2003, Concursal española. No obstante, podría discutirse en el plano doctrinal y jurisprudencial práctico si resulta aplicable analógicamente el Art. 26.1 b) LCA, el cual legitima a cualquiera de las partes contractuales para dar por finalizado el contrato en cualquier momento sin necesidad de preaviso cuando la otra parte hubiera sido declarada en concurso.

Por último, el contrato podrá resolverse unilateralmente por incumplimiento de alguna de las obligaciones contractuales pactadas. Particularmente por el incumplimiento de las obligaciones básicas que caracterizan el sistema de distribución selectiva, como son la prohibición de revender los bienes objeto del contrato a distribuidores ajenos a la red, sea por el proveedor o sea por el distribuidor autorizado, la venta de los productos del proveedor fuera de los establecimientos autorizados en el contrato o en una forma que desvirtúe la esencia del sistema de distribución selectiva comprometiendo el prestigio de la marca del proveedor. No podrá considerarse justa causa de resolución unilateral del contrato el incumplimiento puntual de obligaciones de pago o de defectuosa presentación de los productos o asistencia preventa $\mathrm{y}$

41 Sobre la extinción del contrato de distribución selectiva vid., in extenso, Carbajo Cascón, F., "El contrato de distribución selectiva", cit., pp. 858 y ss. 
postventa por el distribuidor, o el incumplimiento puntual (meros retrasos o envío de productos defectuosos) en el suministro por parte del proveedor; antes bien, deberá acreditarse un incumplimiento grave o incumplimientos reiterados o continuados en el tiempo por cualquiera de las partes.

A diferencia de lo visto para el contrato de agencia y, con condiciones, para el contrato de concesión comercial, la extinción del contrato de distribución selectiva no dará derecho al distribuidor a exigir indemnizaciones por clientela al proveedor; ni siquiera en los casos en que, al combinar criterios de selección cualitativos y cuantitativos, el proveedor hubiera atribuido al distribuidor autorizado una exclusiva territorial. Y es así, porque, en este caso el negocio del distribuidor autorizado no depende (o no esencialmente) de los productos del proveedor, ya que están expresamente prohibidas las exclusivas de producto (marca única o venta exclusiva, propia de la concesión comercial), por lo que la extinción del contrato no le impedirá continuar su explotación con la reventa de productos de empresarios competidores. Además, es sumamente discutible que la actividad del distribuidor genere nueva clientela para el proveedor, pues el sistema se basa por lo general en alto prestigio o reputación de la marca del proveedor, de manera que la marca la que atrae clientela (salvo prueba en contrario) al establecimiento del distribuidor autorizado, de modo que con la extinción no se producirá una situación de enriquecimiento injustificado del proveedor.

Sin embargo, el distribuidor autorizado podrá exigir indemnizaciones por daños y perjuicios en caso de ruptura intempestiva del contrato por el proveedor (sin preaviso o con un preaviso irrazonable), al entenderse efectuada de mala fe. Naturalmente, ambas partes podrán ejercitar acciones de indemnización por daños consecuentes del incumplimiento contractual de la otra parte; especialmente, en el caso del proveedor, cuando el distribuidor rompa el pacto fundamental de prohibición de reventa de productos a distribuidores ajenos a la red.

En cuanto al problema del stock o remanente en poder del distribuidor tras la extinción del contrato, salvo que el contrato contenga estipulaciones específicas sobre el destino que deba darse al remanente (compra por el proveedor a precio de suministro; venta libre a terceros por el distribuidor durante un plazo determinado), habrá que entender que -por aplicación del principio de agotamiento de la marca- el distribuidor podrá revender libremente los productos que adquirió del proveedor para su reventa hasta que agote las existencias, en los mismos establecimientos señalados en el contrato de distribución selectiva e incluso utilizar los signos distintivos del proveedor para designar o describir al público el producto que pone a la venta. Eso sí, el distribuidor no podrá presentarse más como distribuidor autorizado, ni hacer un promoción activa de tales productos ni ofrecer servicios de asistencia antes y después de la venta, por ser éstos elementos característicos del contrato extinto.

Otra posible solución barajada por la doctrina es que, en casos de resolución intempestiva del contrato por el proveedor, pueda incluirse dentro de la reclamación de indemnización por daños y perjuicios ejercitada por el distribuidor, la obligación 
del proveedor de abonar el precio pagado en su día por las mercancías por parte del distribuidor, obligándose éste, una vez recibida la indemnización, a devolver esos productos al proveedor para evitar así situaciones de enriquecimiento injustificado.

\section{EL CONTRATO DE FRANQUICIA}

\section{Concepto, clases y caracteres principales de la franquicia}

Por el contrato de franquicia el principal o franquiciador cede, a cambio de una contraprestación económica fija y/o variable, la explotación de un modelo concreto de negocio a un tercero o franquiciado para una zona de influencia territorial o demográfica, se gira el negocio en el tráfico bajo una marca o signo de empresa (nombre comercial, rótulo de establecimiento) de notoriedad o renombre titularidad del franquiciador, con una presentación comercial uniforme de los establecimientos, incluida en la cesión, en su caso, las patentes y/o secretos industriales necesarios para el desarrollo de la actividad, y comprometiéndose el franquiciado a usar los signos distintivos del franquiciador y a respetar las pautas de organización, marketing y calidad establecidas por el principal para toda la red $^{42}$.

Este contrato complejo se sustancia básicamente en la cesión del derecho de explotación de un modelo de negocio ("franchise format business"), que puede consistir en la mera distribución de productos fabricados o distribuidos por el franquiciador (franquicia de distribución), en la prestación de servicios creados por el franquiciador (franquicia de servicios) o en la fabricación y distribución de productos de acuerdo con los métodos y técnicas desarrollados por el franquiciador (franquicia industrial o de empresa). En todo caso, la cesión del modelo de negocio comprenderá el uso de una marca, nombre comercial y/o rótulo de establecimiento, además de la presentación uniforme de los locales y del personal y medios de transporte del negocio, la comunicación del saber hacer o know how técnico y/o comercial de la empresa, así como la formación del personal y asistencia técnica continuada durante

42 El contrato de franquicia fue reconocido por primera vez como contrato autónomo con la célebre Sentencia del Tribunal de Justicia de las Comunidades Europeas de 28 de enero de 1986 (As. 161/84, "Pronuptia de París c. Schillgalis"). En España, el Tribunal Supremo viene reconociendo autonomía al contrato de franquicia desde hace tiempo, y ha contribuido a perfilar sus contornos (Cfr., SSTS de 15 de mayo de 1985, 27 de septiembre de 1996 ó 30 de abril de 1998). Actualmente, existe en España una definición legal simple de la franquicia en el Art. 62.1 de la Ley 7/1996, de 15 de enero, de Ordenación del Comercio Minorista (LOCM), según el cual "La actividad comercial en régimen de franquicia es la que se lleva a efecto en virtud de un acuerdo o contrato por el que una empresa, denominada franquiciadora, cede a otra, denominada franquiciada, el derecho a la explotación de un sistema propio de comercialización de productos o servicios". 
la vigencia del contrato ${ }^{43}$.

Asimismo es posible distinguir entre franquicia ordinaria o franquicia común y franquicia principal o franquicia maestra ("Master Franchise"), en la cual, una empresa, el franquiciador, entrega a otra, el franquiciado, a cambio de una contraprestación financiera directa o indirecta o ambas, el derecho de explotar una franquicia con la finalidad de concluir acuerdos de franquicia con terceros, los franquiciados, conforme al sistema definido por el franquiciador, asume el franquiciado principal el papel de franquiciador en un mercado determinado ${ }^{44}$. Esto es, la franquicia maestra es aquella en la que el principal o responsable de un modelo de negocio autoriza a un tercero (franquiciado principal o maestro) a crear una red de franquiciados subordinados en un territorio determinado, actúa frente a éstos como franquiciador según el modelo de explotación ideado y desarrollado por el franquiciador principal. Así, entre el fabricante o franquiciador principal y los franquiciados subordinados o de base no se establece ninguna relación jurídica ${ }^{45}$. Es un modelo que opera habitualmente en la distribución internacional, actuando el franquiciado principal o maestro como importador exclusivo que organiza luego la distribución interna por medio de franquiciados subordinados.

Naturalmente, la franquicia supone un acuerdo vertical entre empresarios situados en segmentos distintos de la cadena de valor productivo: el fabricante y un distribuidor; en el caso de la franquicia maestra o principal la relación se da entre el fabricante y el importador exclusivo, por un lado, y entre éste (como franquiciador) y el franquiciado subordinado. Se trata de un contrato escindido del contrato de concesión y que va más lejos en la relación de integración vertical entre principal y distribuidor ${ }^{46}$. De hecho, en la concesión se percibe fácilmente la distinta personalidad y autonomía jurídica y económica del concesionario frente al concedente, mientras que en la franquicia el público identifica generalmente cada establecimiento franquiciado con la empresa del principal o franquiciador, hasta el punto que los establecimientos franquiciados se presentan como sucursales o entidades filiales del franquiciador, de modo que la individualidad empresarial del franquiciado pasa a manifestarse, prácticamente, sólo

43 Véase, en estos términos, el Art. 2.1 del Real Decreto 201/2010, de 26 de febrero, por el que se desarrolla el ejercicio de la actividad comercial en régimen de franquicia y la comunicación de datos al registro de franquiciadores, el cual desarrolla el Art. 62 LOCM sustituyendo al anterior Real Decreto 2485/1998, de 13 de noviembre.

44 Definición de franquicia maestra contenida en el Art. 2.2. del citado Real Decreto 201/2010, de 26 de febrero, por el que se desarrolla el ejercicio de la actividad comercial en régimen de franquicia.

45 Vid. Broseta Pont, M./Martínez Sanz, F., Manual de Derecho Mercantil, Vol. I, 17ª ed., Tecnos, Madrid, 2010, pp. 133-134.

46 No obstante, la doctrina distingue entre franquicias basadas en sistemas de subordinación ("Subordinations-Franchising") y franquicias basadas en sistemas de equilibrio ("PartnerschaftsFranchising"), más propias de franquicias de distribución en sentido estricto, en las que el franquiciado desarrolla el negocio franquiciado sin injerencias del franquiciador y participa en la configuración de la política comercial del sistema de distribución en el que se integra. 
desde un plano jurídico, en el sentido de que el mismo se mantiene como un centro autónomo de imputación patrimonial de los resultados dimanantes de la realización de su actividad en el tráfico, fuera de lo cual su identidad se difumina en la unidad de imagen empresarial que ofrece la cadena de franquicia ${ }^{47}$.

El franquiciador consigue de este modo explotar su modelo de negocio en cualquier parte del mundo al asumir un riesgo mínimo (ya que atomiza el riesgo empresarial entre todos los componentes de la red de franquiciados) y controlando en todo momento la imagen y prestigio de sus signos distintivos, así como la calidad de los productos y servicios ofrecidos por los franquiciados. Éstos, por su parte, se aprovechan intensamente del prestigio o "goodwill" de la marca y del modelo de negocio del principal, sin tener que hacer grandes esfuerzos en la captación de clientela, asociada en todo caso al reclamo que suponen los signos y modelos empresariales del franquiciador.

Por lo demás, como el resto de contratos de distribución indirecta integrada, el contrato de franquicia es un contrato complejo de colaboración independiente entre empresarios, de duración o tracto sucesivo y basado en la confianza recíproca en la estructura empresarial de la contraparte (intuitus instrumentii) ${ }^{48}$. Es además, por lo general, un contrato de adhesión con condiciones generales predispuestas por el franquiciador de manera uniforme para todos los miembros de la red, por lo que estará sometido al control de las condiciones generales previsto en la legislación ${ }^{49}$.

\section{Contenido del contrato}

Por lo que se refiere a las obligaciones del franquiciador destaca la obligación principal de hacer partícipe al franquiciado del modelo de negocio o sistema empresarial de la franquicia, lo cual incluye la autorización para usar los signos distintivos característicos de la empresa y la comunicación y autorización de uso del know how o saber hacer (secreto empresarial entendido en sentido amplio, incluido no solo conocimiento técnicos, sino también comerciales y de marketing, financieros y de gestión). En consecuencia, puede decirse que el franquiciador no cumple con una obligación meramente pasiva de autorizar el uso y disfrute del modelo de negocio,

47 Vid. sobre los sistemas de franquicia, SANTINI, G., El Comercio, cit., pp. 86 y ss.; Echebarría Sáenz, J.A., El contrato de franquicia, McGraw-Hill, Madrid, 1995, pp. 377 y ss. Vid. también Hernando Jiménez, A., El contrato de franquicia de empresa, Civitas, Madrid, 2000, pp. 494 y ss.; y Domínguez García, M.A., "El contrato de franquicia", en Bercovitz Rodríguez-Cano, A./Calzada Conde, Ma A. (Dir.), Contratos Mercantiles, Vol. I, Thomson-Reuters Aranzadi, Madrid, 2009, pp. 876 y ss.

48 Sobre los caracteres básicos de la franquicia, vid. Domínguez García, M.A., "El contrato de franquicia", cit., pp. 885 y ss.

49 Ley 7/1998, de 13 de abril, sobre Condiciones Generales de la Contratación. Vid. Domínguez García, M.A., "El contrato de franquicia”, cit., pp. 890 y ss. 
sino que, todo lo contrario, deberá colaborar activamente con el franquiciado en la implementación y desarrollo del modelo de negocio objeto del contrato, lo que incluye, entre otras obligaciones concretas, la de impartir instrucciones técnicas y comerciales precisas, además de prestar la asistencia técnica y comercial necesaria para el correcto desarrollo del negocio durante todo el tiempo de duración del contrato, asistencia en la formación de personal, e información sobre productos y técnicas de distribución o prestación de servicios. En la misma línea, en interés de toda la red de franquicia, el franquiciador asume una obligación de inspección y control de cada uno de los franquiciados, para velar por una correcta ejecución del contrato y preservar la imagen comercial de la marca y la calidad técnica de las prestaciones.

También deberá el franquiciador respetar la zona de exclusiva o de influencia (territorial y/o demográfica) reconocida al franquiciado, la cual garantiza a éste un aprovechamiento inmediato de la clientela asociada a la marca ${ }^{50}$.

Dado el elevado grado de integración empresarial existente en los sistemas de franquicia, podrá comprenderse que no son extrañas las situaciones de abuso por parte del franquiciador, el cual, aprovechándose del prestigio de su marca y modelo de negocio, exige altas cuotas o cánones de entrada al negocio y porcentajes sustanciales en la participación de beneficios del franquiciado; lo cual, junto a la nula independencia organizativa y reducida autonomía funcional del distribuidor, ha provocado que en algunos países se hayan promulgado normas sectoriales dirigidas a controlar a los franquiciadores (para evitar las "franquicias de humo") y ofrecer a los interesados la oportunidad de obtener una información suficiente y veraz sobre el negocio del franquiciador antes de aventurarse a cerrar acuerdos de franquicia.

Por ejemplo, en España, el Art. 62.2 de la Ley de Ordenación del Comercio Minorista (LOCM) establece que las personas físicas o jurídicas que pretendan desarrollar en territorio español la actividad de franquiciadores, deberán comunicar el inicio de su actividad en el plazo de tres meses desde su inicio al Registro de Franquiciadores, que recogerá los datos exigidos reglamentariamente en el Real Decreto 201/2010, de 26 de febrero. Con carácter complementario, para evitar contrataciones apresuradas por parte de los interesados en obtener una franquicia "cegados" por el esplendor derivado de una marca de prestigio y un modelo de negocio muy sugerente, el Art. 62.3 LOCM dispone que, con una antelación mínima de veinte días a la firma de cualquier contrato o precontrato de franquicia o entrega por parte del futuro franquiciado al franquiciador de cualquier pago, el franquiciador deberá haber entregado al futuro franquiciado por escrito la información necesaria para que pueda decidir libremente y con conocimiento de causa su incorporación a la red de

50 En la delimitación del alcance de la zona de influencia territorial o demográfica y de los precios de reventa juega un papel fundamental la normativa sobre defensa de la competencia; en particular, en Europa, el ya citado anteriormente Reglamento (UE) No. 330/2010 de la Comisión sobre acuerdos verticales, del que nos ocuparemos en la segunda parte de este trabajo. 
franquicia y, en especial, los datos principales de identificación del franquiciador, descripción del sector de actividad del negocio objeto de franquicia, contenido y características de la franquicia y de su explotación, estructura y extensión de la red y elementos esenciales del acuerdo de franquicia. Asimismo se establece que reglamentariamente se establecerán las demás condiciones básicas para la actividad de cesión de franquicias. Todos los aspectos concretos relativos a la información precontractual y al registro de franquiciadores se contienen en el mencionado Real Decreto 201/2010, de 26 de febrero.

En cuanto a las obligaciones del franquiciado, éste asume la obligación básica de abonar el canon de entrada o cuota de ingreso a la red de franquicias ("entry fee"), así como una cuota fija o variable (creciente o decreciente) periódica que dependerá del volumen de facturación de su negocio (regalías o "royalties"), aunque en ocasiones el pago puede consistir en una cuota única o a tanto alzado ("a forfait"). Asimismo tendrá como segunda obligación básica explotar el negocio objeto del contrato con la diligencia debida de un ordenado empresario y de acuerdo con las exigencias de la lealtad y de la buena fe contractual, y también con lealtad a los intereses del conjunto de miembros (franquiciador y franquiciados) que integran la red de distribución. Como obligación extendida o derivada de la anterior surge la de respetar la imagen comercial de la red de distribución asociada a la marca o nombre comercial, lo cual implica usar en todo momento los signos distintivos del principal ${ }^{51}$, respetar la disposición comercial del establecimiento (lo que incluye no sólo la presentación comercial del local de negocio, sino también de los empleados y de los vehículos de transporte) y seguir las instrucciones de carácter técnico y comercial (marketing) impartidas por el franquiciador.

Con carácter complementario, por el hecho de integrarse en la red de distribución creada por el franquiciador y la necesidad de mantener una imagen uniforme de la misma, el franquiciado asume la obligación de someterse a las instrucciones técnicas, comerciales y publicitarias impartidas por el franquiciador, así como a los controles e inspecciones periódicas que éste decida ejercer sobre su actividad.

Asimismo, el franquiciado asume -mediante pactos expresos de confidencialidaduna importante obligación de secreto, que se conforma como expresión del deber genérico de lealtad y buena fe contractual y se concreta en la obligación de no desvelar los secretos industriales y comerciales (know how, en forma de técnicas industriales y comerciales o de modelo de negocio, técnicas de marketing, de formación de personal, contables o financieras) que le hubieran sido comunicados

$51 \quad$ Así es, mientras en la concesión comercial y la distribución selectiva el principal autoriza al distribuidor el uso de sus marcas o signos distintivos en una determinada forma, pero sin prohibir el uso de signos distintivos propios del distribuidor, en la franquicia el franquiciado no sólo tiene derecho a usar los signos del franquiciador sino que tiene la obligación de usar solo esos signos, no pudiendo hacer un uso comercial de sus propios signos distintivos (los cuales, por tanto, se reservan al plano estrictamente jurídico-contractual). 
por el franquiciador, el cual se prolonga incluso una vez finalizado el contrato; pacto de confidencialidad que estará sujeto a importantes cláusulas penales para evitar su incumplimiento ${ }^{52}$.

\section{Extinción de la franquicia e indemnizaciones}

La extinción del contrato de franquicia podrá tener lugar por las mismas causas que el contrato de concesión comercial, incluida -en el caso de contratos de duración indefinida- la resolución por incumplimiento grave o continuado de las obligaciones de las partes ${ }^{53}$ y la resolución unilateral o desistimiento contractual ad nutum de una de las partes, que podrá dar lugar a indemnización por daños y perjuicios si se hiciera de mala fe o de forma abusiva, como puede ser la resolución intempestiva o con un plazo de preaviso insuficiente ${ }^{54}$.

Aunque se discute en doctrina y jurisprudencia, en líneas generales no parece que proceda la indemnización por clientela en la extinción de contratos de franquicia por resolución unilateral sin justa causa del franquiciador o por resolución unilateral del franquiciado por causa imputable al primero, pues en todo caso puede decirse que el fondo de comercio propio del negocio del franquiciado es siempre del franquiciador; es decir, que la clientela está asociada al modelo de negocio y signos distintivos del franquiciador, ya que los distribuidores o franquiciados no se presentan externamente en el tráfico como empresarios independientes, sino como meras sucursales o filiales del empresario principal ${ }^{55}$.

No obstante, dado el auge de este sistema de distribución en el mercado minorista actual, habrá que estar al caso concreto, puede haber lugar para la discusión en aquellas franquicias donde la marca o signos distintivos no tengan un amplio reconocimiento entre el público, ya que, en tales casos, podrá valorarse el esfuerzo del franquiciado en la captación y fidelización de clientela que pasa a engrosar el fondo de comercio del franquiciador una vez extinguido el contrato ${ }^{56}$. En todo caso, acreditado el incremento de clientela como consecuencia de la actividad del

52 Además, el acto de revelar secretos industriales constituye un ilícito de competencia desleal, de acuerdo con lo previsto en el Art. 13 de la Ley 3/1991, de 10 de enero, de Competencia Desleal española, y también en el Art. 16 de la Ley 256 de 1996 colombiana.

53 Cfr., Sentencia del Tribunal Supremo español de 1 de junio de 2009, que admite la resolución unilateral por incumplimiento por el franquiciador de sus obligaciones de asistencia técnicacomercial continuada.

54 Cfr., Sentencia del Tribunal Supremo español de 16 de marzo de 2007. Ampliamente, sobre la extinción del contrato de franquicia y abogando por no hacer una aplicación extensiva (en forma de subsunción normativa) de la indemnización por clientela en la agencia comercial (Art. 28 LCA) al contrato de franquicia, salvo en supuestos muy excepcionales donde se pueda acreditar que el franquiciado actúe de hecho como agente comercial, vid. DOMÍNGUEZ GARCÍA, "El contrato de franquicia", cit., pp. 911 y ss.

55 Vid. Sentencia del Tribunal Supremo español de 31 de julio de 2007.

56 Cfr., STS de 1 de junio de 2009. 
franquiciado al tiempo de producirse la extinción contractual, la circunstancia objetiva de la mayor o menor notoriedad de la marca del franquiciador podrá emplearse por Jueces y Tribunales como factor de determinación del quántum indemnizatorio, en el entendimiento de que cuanto mayor notoriedad menor esfuerzo de captación habrá tenido que hacer el franquiciado y menor también será el aprovechamiento o enriquecimiento obtenido por el franquiciador (pues puede considerarse clientela natural de la marca y no del distribuidor), por lo que la cuantía indemnizatoria deberá reducirse proporcionalmente ${ }^{57}$.

\section{IMPACTO DE INTERNET PARA LA DISTRIBUCIÓN COMERCIAL. NUEVAS FORMAS DE DISTRIBUCIÓN COMERCIAL EN EL MERCADO VIRTUAL}

\section{El fenómeno heterogéneo de la distribución comercial en Internet}

Internet se ha presentado desde sus orígenes como un instrumento o mecanismo de desintermediación, que amenaza con destruir o reducir notablemente los modelos o sistemas clásicos de distribución indirecta, simple o integrada, que favorece la distribución directa por parte de los proveedores de bienes y servicios. Sin embargo, la Red constituye un gigantesco escaparate para todos los operadores económicos, incluidos los distribuidores tradicionales establecidos en el mercado físico o presencial, que no renuncian a utilizar el nuevo canal para el desarrollo de su actividad. Además, el nuevo medio ha facilitado la aparición de nuevos e interesantes modelos de negocio basados, unos, en la distribución en línea de bienes digitalizados (sitios de suministro de música u otras creaciones intelectuales digitalizadas) y, otros, en la mediación o intermediación contractual (sitios de subastas electrónicas o sitios de mediación en línea) $)^{58}$.

Puede entenderse, entonces, fácilmente, que la aparición de un medio de comunicación universal que permite al fabricante o prestador de servicios contactar y negociar directamente con los consumidores y usuarios, amenaza la supervivencia a medio plazo de los sistemas o modelos tradicionales de distribución indirecta, simple e integrada. Los fabricantes o proveedores tenderán a canalizar las ventas

57 Cfr., Sentencia de la Audiencia Provincial de Barcelona, Sección 15a , de 10 de junio de 2004. Vid. sobre esta problemática, Vaquero Pinto, Ma. J., "La terminación de los contratos de distribución", cit., p. 346.

58 Para una descripción general y amplia del fenómeno de la distribución comercial en Internet, vid. Carbajo Cascón, F., "La Distribución en Internet", en Herrero García, Ma. J. (Dir.), La Contratación en el Sector de la Distribución Comercial, Thomson-Reuters Aranzadi, Navarra, 2010, pp. 163 y ss. 
de sus productos o la prestación de sus servicios mediante la negociación directa con los consumidores, sal ubcontratar luego el almacenamiento y envío a domicilio mediante un número reducido de almacenistas y porteadores; lo cual provocará la desaparición gradual de distribuidores mayoristas y minoristas. Este fenómeno es mucho más evidente cuando se trata de bienes y servicios susceptibles de digitalizarse y ponerse a disposición del cliente directamente mediante una transmisión en línea a través de la Red, como sucede con todos las obras intelectuales y prestaciones industriales conexas tuteladas por derechos de autor y derechos afines; en estos casos la desaparición de intermediarios tradicionales es prácticamente absoluta.

Sin embargo, la desaparición de intermediarios en la distribución no será total. Aunque se produzca un crecimiento de la distribución directa del proveedor al consumidor, los sistemas de distribución indirecta, sobre todo los modelos de distribución indirecta integrada permanecerán aún durante muchos años, pues se basan en una estrategia postindustrial de competitividad basada en el prestigio de la marca que se construye sobre una cuidada presentación comercial en establecimientos abiertos al público y la asistencia al cliente antes y después de la venta. Y, lógicamente, los distribuidores integrados -que son en todo caso empresarios independientesquerrán también acceder al mercado virtual de Internet para ampliar sus expectativas de negocio, pues, entran en conflicto en ocasiones con los proveedores que quieren reservarse en exclusiva al canal de distribución virtual y con los otros miembros de la red comercial si ésta se sustenta sobre exclusivas territoriales. De este modo, la distribución presencial o tradicional por parte de distribuidores integrados en una red comercial creada por el proveedor y la distribución en línea por el proveedor y los propios distribuidores integrados se solaparán, aunque se produzca una reducción paulatina en el número de intermediarios, en tanto en cuanto, los proveedores no impulsarán nuevas contrataciones ${ }^{59}$.

Por otro lado, la más que posible reducción paulatina de intermediarios tradicionales, contrasta con la aparición de nuevos modelos de intermediación en la contratación y circulación de bienes y servicios. Se trata de sitios en línea que actúan como grandes agregadores de oferta y demanda dispersa y que, en muy poco tiempo, se han perfilado como nuevos sistemas o modelos que, sin ser estrictamente distribuidores, contribuyen a la distribución de bienes y servicios a través de Internet. De hecho, son utilizados frecuentemente por los proveedores y distribuidores (integrados e independientes, incluidos comerciantes paralelos ajenos a las redes de distribución creadas por los fabricantes o proveedores) para realizar sus ofertas y colocar sus prestaciones entre otros distribuidores y entre el público.

59 El problema del acceso al mercado de Internet de los distribuidores integrados, como concesionarios, distribuidores autorizados y franquiciados, se analizará con detalle en la segunda parte de este trabajo, cuando se trate de los aspectos de derecho de la competencia y derecho marcario de la distribución comercial. 
En este nuevo aspecto de la distribución comercial "on line" presenta novedosos perfiles contractuales que conviene analizar con mayor detalle para completar el mapa contractual de la distribución comercial.

\section{La distribución en Internet a través de agregadores de información comercial}

Los denominados "agregadores de información comercial" ponen a disposición de terceros una plataforma de promoción y encuentro comercial a disposición de oferentes y demandantes para favorecer así relaciones comerciales entre multitud de sujetos dispersos por todo el planeta ("many to many relations"). Agregadores de información comercial pueden ser las plataformas de oferentes de determinadas prestaciones (centrales de ventas). También las plataformas de demanda (centrales de compras) y, en particular, de agregación de consumidores de un tipo concreto de productos o servicios (clubes o comunidades de compra). Pero los agregadores más característicos y relevantes son los sitios de intermediación on line que (como los sitios de subastas eBay o mercadolibre.com) se limitan a poner los medios digitales necesarios para "agregar" oferta y demanda de la más variada naturaleza entre empresarios (comercio electrónico "Bussines to Bussines" ó B2B), entre éstos y consumidores (comercio electrónico "Bussines to Consumer" ó B2C) e incluso entre particulares (comercio electrónico "Consumer to Consumer" ó $\mathrm{C} 2 \mathrm{C}$ ), actuando así como corredores o mediadores en línea.

Estos agregadores de información constituyen un nuevo tipo de intermediarios que contribuyen a la distribución de productos y servicios en red, sin que, en rigor, puedan calificarse como distribuidores (ni simples, ni integrados), ya que su función se limita a organizar una plataforma centralizada para la compra o venta de prestaciones empresariales concretas, o bien una plataforma o punto de encuentro en línea para todo tipo de oferentes y demandantes, sirven así a la distribución de prestaciones sin asumir posiciones de distribuidores en sentido estricto. De modo que los agregadores no son, en sentido estricto, distribuidores, pero contribuyen de manera significativa a la contratación en línea y distribución de prestaciones de todo tipo, pues racionalizan la distribución a través de Internet (e-distribution). Por ello, suele calificarse a estos nuevos modelos de negocio como formas especiales de distribución en Red.

El fenómeno de los agregadores es característico de la economía en red o economía de la sociedad de la información ("e-economy"), y encuentra su explicación en el llamado Efecto de Red ("Network Effect"). Los efectos o externalidades de red son un nuevo fenómeno económico que se produce cuando la utilidad que un usuario o consumidor obtiene del uso o consumo de un bien aumenta en función del 
número de usuarios o consumidores adicionales de dicho bien ${ }^{60}$. Los agregadores son capaces de atraer masivamente oferentes y demandantes de todo el mundo, gracias al valor que supone la existencia de un punto de encuentro universal para la oferta y demanda dispersa; lo cual explica la tendencia gradual a la existencia de un número reducido de agregadores, hasta el punto de que estos sitios de encuentro o plataformas electrónicas de intermediación llegan a constituir auténticos mercados independientes; mercados en sí mismos, dentro del caótico ciberespacio comercial o mercado de mercados creado en la Red. Como se ha dicho ya, en estos mercados de agregación tienen lugar indistintamente operaciones de comercio electrónico entre empresarios o profesionales (B2B), entre empresarios o profesionales y consumidores (B2C) y entre consumidores o particulares (C2C). De manera que es común hablar, según el tipo de operaciones que predominen, de "B2B e-market places", "B2C e-market places" y "C2C e-market places". Asimismo, los mercados de agregadores pueden clasificarse en abiertos o cerrados, en función de si permiten un acceso libre o se restringen a un círculo concreto de oferentes y/o demandantes ("public or private business communities").

En estos mercados es preciso distinguir, en el plano contractual, la relación jurídica que se establece entre el intermediario o agregador y sus clientes de la relación jurídica que se produce entre clientes de la misma plataforma cuando el agregador actúa como un intermediario puro. El agregador presta un servicio de la sociedad de la información ${ }^{61} \mathrm{y}$, por tanto, se aplicarán las reglas sobre contratación a distancia por medios electrónicos; asimismo, cuando los clientes sean consumidores, los agregadores deberán cumplir las obligaciones de información exigidas por la normativa de comercio electrónico y, en su caso, de ventas a distancia. De otro lado, las operaciones cerradas entre clientes de la misma plataforma (en los casos de agregadores que actúan como intermediarios puros) se ajustarán también a las reglas sobre contratación electrónica y, en el caso de comercio electrónico B2C, al régimen de los contratos con consumidores celebrados a distancia por medios electrónicos.

En consecuencia, para la perfección del contrato a distancia se estará a lo dispuesto en los Arts. 1262 del Código Civil español y del Art. 54 del Código de comercio español $^{62}$. Además se aplicarán las reglas sobre contratación electrónica previstas

60 Esto significa que cuantos más usuarios utilicen un determinado producto o servicio, el valor de éste se incrementa exponencialmente: aumenta su utilidad y resulta más atractivo para un usuario individual conforme se incrementa el número de usuarios que tienen acceso al mismo.

61 Entendiendo por tal en el entorno jurídico de la Unión Europea, "todo servicio prestado normalmente a título oneroso, a distancia, por vía electrónica y a petición individual del destinatario". Cfr., Anexo A) de la Ley 34/2002, de 11 de julio, de servicios de la sociedad de la información y del comercio electrónico (LSSICE).

62 Según los cuales (de idéntica redacción), hallándose en lugares distintos el que hizo la oferta y el que la aceptó, hay consentimiento desde que el oferente conoce la aceptación o desde que, habiéndosela remitido el aceptante, no pueda ignorarla sin faltar a la buena fe. En los contratos celebrados mediante dispositivos automáticos hay consentimiento desde que se manifiesta la 
en el Título IV de la Ley 34/2002, de 11 de julio, de servicios de la sociedad de la información y del comercio electrónico, especialmente lo relativo a la información precontractual y postcontractual (Arts. 23-29 LSSICE) ${ }^{63}$. Y si la contratación se produce con consumidores (tanto en el servicio que presta el intermediario como en la contratación de bienes o servicios) se aplicarán las reglas sobre protección de consumidores en la contratación a distancia establecidas en el Texto Refundido de la Ley General para la Defensa de Consumidores y Usuarios aprobado por el Real Decreto legislativo 1/2007, de 16 de noviembre (Arts. 92-106).

\subsection{Centrales de ventas y compras}

Las centrales de ventas y compras consisten en una agregación de la oferta y/o de la demanda a partir de un solo sitio en línea, con la clara intención de organizar de manera más eficiente las relaciones comerciales dentro de la Red. Estas plataformas son realmente aplicaciones de "software" que permiten reunir o agregar a oferentes y demandantes de productos o servicios similares, para racionalizar sus operaciones económicas de compra, venta o prestación y recepción de servicios bajo sistemas informáticos y técnicas comerciales compartidas. Se trata, en suma, de una forma de logística empresarial compartida con la finalidad de ahorrar costes a todos los miembros de la plataforma y también a los terceros que contactan con ellos a través de ella; una original modalidad de "e-logística" basada en el aprovechamiento del valor económico intrínseco de la información: la organización racional de la información aporta un alto grado de transparencia y permite reducir sustancialmente los costes de agencia (prescindiendo de intermediarios tradicionales) y de transacción (el acuerdo se hace sobre bases firmes y está automatizado.

Cuando los destinatarios de las ofertas o demandas agregadas en la plataforma son otros empresarios se estará ante plataformas "Business to Business" o B2B

aceptación. De modo que en la contratación mediante correo electrónico (mail to mail) el contrato se perfecciona cuando el mensaje de aceptación se aloja en el buzón del oferente, ya que este no puede ignorar que ha recibido la aceptación sin faltar a la buena fe, pues le basta consultar su buzón para detectar el mensaje y abrirlo para ver su contenido. En la contratación en plataformas Web estamos ante una contratación mediante dispositivos, basta pulsar el botón de aceptación para entender que se manifiesta la aceptación y que, por tanto, se perfecciona el contrato.

En Colombia, la Ley 527 de 1999 recoge las Leyes Modelo sobre Comercio Electrónico y Firma Electrónica de UNCITRAL (CNUDMI), asumiendo que la oferta y aceptación pueden emitirse mediante un mensaje de datos electrónico (principio de equivalencia funcional, ex Arts. $14 \mathrm{y}$ 15), aunque no establece una norma específica sobre la perfección del contrato a distancia, por medios electrónicos. Será preciso recurrir al Art. 864 del Código de Comercio colombiano, el cual, obviamente, no está adaptado a la nueva realidad tecnológica, pero sirve para determinar como momento de conclusión o perfección del contrato el de recepción de la aceptación por el proponente.

63 En la Ley 527 de 1999 de Colombia se establecen previsiones en relación con la confirmación de la recepción de mensajes de datos de acuerdo con lo que dispongan las partes (Cfr., Arts. 20 22), pero no se establecen obligaciones de información precontractual, por lo que parece pensar fundamentalmente en el comercio electrónico entre empresarios o B2B. 
(plataformas interempresariales). Son realmente foros virtuales de agrupación de la oferta o demanda empresarial de un sector de actividad para facilitar el contacto con los demandantes $\mathrm{u}$ oferentes de sus prestaciones o actividades bajo un sistema y reglas comunes. Estas plataformas pueden adoptar formas muy diversas y ser de tipo sectorial o general, horizontales o verticales, operar mediante directorios que muestran listados de empresarios y de productos, servicios o actividades (muestran sus respectivos precios y condiciones) o bien seguir el modelo de la subasta electrónica tanto en la oferta como en la demanda de bienes y servicios. Los modelos de negocio seguidos se suelen clasificar en centrales de ventas y centrales de compras, que pueden presentar en la Red los mismos o parecidos problemas para la competencia que han presentado hasta la fecha en el mercado tradicional.

Si los destinatarios de la oferta empresarial agrupada son consumidores o, por el contrario, son los propios consumidores los que se agrupan en una plataforma común para demandar bienes y servicios empresariales, se está ante plataformas "Business to Consumer" o B2C (plataformas de consumo), que también pueden ser generales o sectoriales, seguir modelos de venta directa, directorios o subastas, u otros. En estos casos, deberán respetarse las exigencias de la normativa sobre protección de consumidores en los contratos a distancia, ya mencionadas.

En ambos casos el operador de la plataforma (central de compras o ventas) presta un servicio de la sociedad de la información que consiste en actuar de intermediario entre los oferentes y los demandantes exclusivamente por medios electrónicos, se cobra un precio a modo de comisión por las operaciones concluidas a través de su plataforma. En ocasiones, el operador del sitio actuará como mandatario o comisionista de los oferentes o de los demandantes, según los casos, celebra contratos con terceros generalmente en nombre propio (comisión indirecta), y se vincula personalmente sin perjuicio de las relaciones internas con su comitente o representado. Este modelo de negocio será común en las centrales de ventas constituidas por asociaciones de empresarios de un sector. En otras ocasiones el responsable del sitio se limita a poner a disposición de terceros oferentes o demandantes una plataforma electrónica para presentar de forma agregada sus ofertas o demandas y facilitar la negociación y conclusión de contratos. En estas situaciones, el operador presta un servicio de intermediación en línea, actúa a modo de alojador de informaciones ("hosting”), por lo que no participa directamente en las operaciones comerciales que se celebren en su plataforma y tampoco resultará responsable de los daños y perjuicios producidos a terceros por los usuarios de su plataforma en línea siempre que no tenga conocimiento efectivo de que la actividad o la información almacenada es ilícita o de que lesiona bienes o derechos de un tercero o, si tienen conocimiento, si actúan con diligencia para retirar los datos o hacer imposible el acceso a ellos ${ }^{64}$.

64 Cfr., Art. 16 LSSI-CE. 


\subsection{Comunidades privadas de compras}

Un tipo específico de central de compras son los denominados clubes privados o comunidades de compras virtuales ("Community Shopping" / "Club Shopping”), por medio de las cuales se ofrece ventajas económicas considerables en la adquisición de productos o servicios de marcas prestigiosas a los socios participantes mediante la venta directa exclusiva a los miembros del club, o bien mediante la agregación de socios demandantes de un mismo producto ("Power shopping").

La práctica -ya conocida antes de la aparición de Internet- ha encontrado su verdadero campo de acción en la Red, por las mayores facilidades de formar comunidad con un número considerable de sujetos interesados. En estas plataformas se ofrece una serie de productos a un precio fijo inferior al precio normal de mercado de esos productos (régimen de "outlet"), o bien se ofrecen productos a un precio de partida que desciende progresivamente según se adquiere un número mayor de unidades por los socios del club, de modo tal que la agregación de adquirentes permita a los participantes obtener los productos ofrecidos a precios muy inferiores al de salida.

En este modelo de negocio el operador de la plataforma (“Co-Shopper") actúa normalmente como comisionista o representante de los oferentes de productos y servicios ofrecidos en su plataforma. Aunque en algunos modelos actúa más bien como representante o comisionista de los demandantes (compradores). Incluso pueden darse situaciones en que actúe bajo una doble comisión. En unos casos, la actividad del intermediario se rige por el mecanismo de la invitación a realizar ofertas a los socios del club de compras ("invitatio ad offerendum"); así, el "Co-Shopper" ofrece a los socios la posibilidad de realizar ofertas para adquirir un producto a un precio fijo (precio de club), o bien al mejor precio o precio más bajo, para lo cual la invitación indicará el número de ofertas necesarias que deben acumularse por los socios del club durante un tiempo determinado. En otras ocasiones el "Co-Shopper" realizará ofertas en firme a un precio fijo o determinable a la baja (en función del número de interesados) para que sea aceptado por los miembros del club durante un plazo establecido.

En todo caso, el operador del club de compra presta un servicio de la sociedad de la información a sus socios por el cual ofrece la oportunidad de celebrar contratos de compraventa de los productos insertados en su sitio. De modo que deberá cumplir con las obligaciones previstas en la legislación sobre comercio electrónico en la legislación española (Arts. 23-29 LSSICE) y con las restantes obligaciones establecidas para protección de los consumidores en los contratos a distancia (Arts. 92-106 TRLGDCU).

\subsection{Puntos de encuentro (corredores en línea)}

El modelo más peculiar de agregadores comerciales es el de los intermediarios puros que organizan plataformas electrónicas que actúan como punto de encuentro 
entre oferentes y demandantes de todo tipo de productos y servicios, se agrega así oferta y demanda dispersa y diversa hasta convertirse en auténticas lonjas virtuales de contratación, ya que son gestionados de manera absolutamente independiente respecto a los participantes en las operaciones comerciales en línea.

Estos operadores no participan en la negociación ni en la contratación, y tampoco se hacen responsables de la ejecución de los contratos. Se limitan a aproximar la oferta y la demanda, actúan como punto de encuentro entre empresarios (B2B), entre empresarios y consumidores (B2C) e incluso entre los mismos consumidores directamente (C2C). Se trata, por tanto, de agregadores independientes de servicios y/o de contenidos que desarrollan un papel de mediadores o corredores "on line", limitándose a poner en contacto a oferentes y demandantes por vías exclusivamente electrónicas a cambio de una pequeña comisión si llega a celebrarse la operación a través de su plataforma.

Estos corredores en línea realizan su actividad mediante diferentes modelos de negocio. En unos casos actúan como auténticas centrales de compraventa mediante sistemas de oferta directa o de invitaciones a realizar ofertas ${ }^{65}$. En otras ocasiones, los corredores gestionan un punto de encuentro para operaciones de trueque o permuta empresarial ${ }^{66}$. Pero, sin duda, los modelos de negocio más populares son los sitios de subastas electrónicas que reúnen oferta y demanda de manera indiscriminada (incluido empresarios o particulares) mediante el sistema de pujas en la fijación de precios ("Online-Auction"), aunque también incluyen ofertas mediante el modelo de precio fijo y venta directa ${ }^{67}$. También se incluye en esta categoría de corredores en línea, los sitios que operan mediante el modelo de subastas inversas o subastas holandesas, en los que un sólo cliente interesado en adquirir un producto o un servicio marca un precio máximo e invita a realizar ofertas inferiores a ese precio a los proveedores de bienes y servicios, cerrándose la operación con el proveedor que realiza la oferta más baja dentro del plazo estipulado ("Reverse Online-Auction"), de manera que existe un solo cliente que recibe ofertas de varios proveedores. Se trata, por lo general, de mercados abiertos en los que se entremezclan operaciones sobre toda clase de bienes o servicios entre empresarios o profesionales (B2B), entre éstos y consumidores (B2C) y entre particulares (C2C). Aunque en algunos casos se restringen a determinados operadores, que gestionan el corredor mercados privados de contratación entre empresarios (B2B) o entre empresarios y consumidores (B2C) según el modelo o sistema de venta directa, el de la subasta tradicional o de la subasta inversa.

De todos ellos, como se ha dicho, los sitios de subastas electrónicas son los más extendidos; de hecho, hoy día constituyen uno de los modelos de negocio más

65 V.gr., el sitio www.adquira.es

66 Vid. el sitio www.acambiode.com

67 Es el caso del popular sitio www.ebay.com, sin duda el mayor mercado de agregación del mundo, y de otros como www.mercadolibre.com. 
característicos de la Red, contribuyen de manera significativa a la contratación y distribución de productos y servicios entre empresarios, profesionales y consumidores de todo el mundo, independientemente de quien ostente en cada caso la condición de oferente o demandante.

En estos sitios hay que diferenciar entre el contrato que sirve de base al servicio de la sociedad de la información que presta el agregador o corredor en línea a sus clientes y los contratos que formalizan las operaciones de compraventa o trueque (permuta) entre los usuarios de la plataforma.

La relación entre el proveedor de bienes y servicios y el prestador del servicio de intermediación (operador de la plataforma) no se sustenta sobre el contrato de subasta $^{68}$, pues, lógicamente, estos intermediarios no son subastadores en sentido estricto (no pueden realizar funciones de custodia y tasación), sino que actúan como meros "puntos de encuentro" ${ }^{99}$. Por tanto, se está ante un contrato de servicios (servicios de intermediación de la sociedad de la información, equiparable a los contratos de "hosting" o alojamiento de informaciones) que puede reconducirse, por las peculiaridades de la actividad desarrollada, al tradicional contrato de corretaje; con la particularidad de que, en este caso, la actividad mediadora del corredor se realiza de forma automatizada por medios electrónicos; se trata, en suma, de un corretaje online ${ }^{70}$. Al margen quedan otras relaciones contractuales previas que normalmente se dan entre el intermediario y el cliente oferente, como son los contratos de servicios por los que el primero ofrece la posibilidad de elaborar anuncios o crear espacios virtuales específicos para las ofertas del cliente. Como contrato celebrado

68 Vid. sobre el contrato de subasta en España, el Art. 57 LOCM.

69 A modo de ejemplo, las Condiciones de Uso del sitio www.ebay.es, indican claramente que eBay no es un subastador tradicional, sino un punto de encuentro: “(...) eBay classic no es un subastador tradicional. En lugar de eso, nuestros sitios Web son un lugar de encuentro donde cualquiera puede ofrecer, vender y comprar casi cualquier cosa, en cualquier momento y desde cualquier procedencia, en una amplia variedad de formatos de precio y lugares, como tiendas, formatos de precio fijo y formatos de subasta. No estamos involucrados en la transacción real entre compradores y vendedores. No controlamos ni garantizamos la calidad, la seguridad o la legalidad de los artículos puestos en venta, la veracidad o la exactitud de los contenidos o los anuncios de los usuarios, la identidad de los usuarios, la capacidad de los vendedores para vender artículos, la capacidad de los compradores para pagar los artículos o el hecho de que los compradores o los vendedores vayan a completar realmente la transacción. No transferimos la propiedad legal de los articulos del vendedor al comprador...".

70 Las Sentencias del Tribunal de Grande Instance de París, $3^{\mathrm{a}}$ Chambre, $1^{\mathrm{a}}$ Secc., de 21 de octubre de 2008 ("Lancôme Parfums et Beautè \& cie. C. Marie B.") y del Tribunal de Grande Instance de Troyes, Chambre civile, de 4 de junio de 2008 ("Hermès International c. Cindy F. et eBay"), que tratan sobre la posible responsabilidad de eBay por la venta de productos de marcas de prestigio por distribuidores no autorizados por el titular de la marca y proveedor de una red de distribución selectiva, consideran que el operador "eBay" no actúa solamente como alojador o albergador de informaciones en línea ("hosting"), sino también como editor o responsable de un sitio de subastas electrónicas, que reconducen -de forma original y acertadamente a mi juicio- a la actividad de corretaje en línea, en tanto en cuanto "e-Bay" obtiene una remuneración en forma de comisión por las ventas que se efectúan a través de su plataforma de intercambios. Pueden consultarse estas sentencias en el sitio www.legalis.net. 
a distancia por medios electrónicos, el intermediario deberá respetar todas las reglas establecidas al respecto en los Arts. 23-29 de la legislación sobre comercio electrónico (LSSICE). Y si celebra contratos con consumidores (como ocurre cuando las operaciones son entre particulares o comercio electrónico $\mathrm{C} 2 \mathrm{C}$ ), deberá observar todas las obligaciones legales establecidas para los contratos celebrados a distancia con consumidores (Arts. 92-106 TRLGDCU).

En cuanto a los contratos celebrados entre los oferentes y demandantes usuarios de la plataforma de encuentro, se aplicarán las reglas generales sobre perfección del contrato ya comentadas ${ }^{71}$, con la particularidad de que el encuentro de la oferta y la demanda se produce dentro de la plataforma del corredor ${ }^{72}$. Por la forma en que se cierran las operaciones utilizando la plataforma y los medios de pago proporcionados por el intermediario ${ }^{73}$,

Aunque el corredor en línea no participe formalmente en estos contratos, sí que lo hace materialmente, pues lo cierto es que tales contratos se celebran en su plataforma con los medios de pago ofrecidos por el propio corredor. Es dudoso, por tanto, si las obligaciones de información de la normativa sobre comercio electrónico y, en las operaciones $\mathrm{B} 2 \mathrm{C}$, las reglas sobre protección de consumidores en los contratos a distancia (Arts. 23-29 LSSICE y Arts. 92-106 TRLGDCU) son imputables al oferente de bienes y servicios o bien al corredor en línea. La globalidad del medio y la dispersión de la oferta y la demanda, complica en exceso la posibilidad de ofrecer una solución razonable a este problema ${ }^{74}$.

\section{REFERENCIAS}

Ávila de la Torre, A., "Consideraciones generales en torno al concurso en los contratos de distribución”, en HERRERO GARCÍA, Ma. J. (Dir.), La Contratación en el Sector de la Distribución Comercial, Thomson-Reuters Aranzadi, Navarra,

71 Cfr., en la legislación española, Arts. 1262 CC y 54 Ccom.

72 En la contratación a través de sitios de intermediación en línea que actúan a modo de corredores y habitualmente mediante sistemas de subastas, debe entenderse que los oferentes realizan ofertas en firme y no meras invitaciones a realizar ofertas a los potenciales adquirentes. De lo contrario, el oferente podría rechazar operaciones en las que el precio de adjudicación en la puja no satisfaga sus pretensiones. Así lo viene declarando el Tribunal Supremo Alemán desde su ya célebre sentencia de 7 de noviembre de 2001 (Caso Ricardo. de).

73 En este contexto, podría resultar aplicable -aunque no sin cautelas- a estas operaciones el Art. 55 del Código de Comercio español, según el cual, los contratos en que intervenga corredor quedarán perfeccionados cuando los contratantes hubieran aceptado su propuesta. Interpretando así que la aceptación de la propuesta se produce cuando el aceptante envía su correo de confirmación a la plataforma del corredor (en la venta directa) o cuando se cierra el periodo de subasta y el corredor adjudica la operación al mejor postor, comunicándolo a las partes.

74 El Art. 93.1 b) TRLGDCU declara que la regulación sobre protección de consumidores en los contratos a distancia no se aplica a las ventas celebradas en subasta, pero sí que se aplica a las ventas celebradas en subastas efectuadas por vía electrónica, por lo que bien podría pensarse que corresponden al subastador (al corredor en línea) el cumplimiento de esas obligaciones frente a los consumidores, al celebrarse todo el proceso contractual a través de su plataforma de encuentro. 
2010, pp. 351 y ss.

Bercovitz Álvarez, R., "El contrato de suministro", en Bercovitz Rodríguez-Cano,

A./ Calzada Conde, Ma. A., (Dir.), Contratos Mercantiles, Tomo I, Thomson-

Reuters Aranzadi, Navarra, 2009, pp. 551 y ss.

Bercovitz Álvarez, R., "El contrato de agencia”, en Bercovitz Rodríguez-Cano, A./

Calzada Conde Ma. A. (Dir.), Contratos Mercantiles, T. I. Thomson-Reuters Aranzadi, 2009, pp. 711 y ss.

Broseta Pont, M./Martínez Sanz, F., Manual de Derecho Mercantil, Vol. I, 17ª ed., Tecnos, Madrid, 2010

Camacho De Los Ríos, J. "Actualidad del contrato estimatorio. Su problemática", en AA.VV. Estudios en Homenaje al Profesor Justino Duque Domínguez, Vol. II., Universidad de Valladolid, 1998, pp. 1207 y ss.

Carbajo Cascón, F., "El contrato de distribución selectiva”, en Bercovitz RodríguezCano, A./Calzada Conde, Ma. A., (Dir.), Contratos Mercantiles, ThomsonReuters Aranzadi, Madrid, 2009, pp. 816 y ss.

Carbajo Cascón, F., La distribución selectiva y el comercio paralelo de productos de lujo, Ibáñez-DePalma-Universidad Javeriana de Bogotá, Santa Fe de Bogotá, 2009

Carbajo Cascón, F., "La Distribución en Internet”, en Herrero García, Ma. J. (Dir.), La Contratación en el Sector de la Distribución Comercial, Thomson-Reuters Aranzadi, Navarra, 2010, pp. 163 y ss.

Carraro, L. Il mandato ad alienare, Cedam, Padova, 1983

Castresana Herrero, A., "Anotaciones críticas al contrato estimatorio: la historia silenciada de un pacto de garantía", en Herrero García, Ma. J. (Dir.), La Contratación en el Sector de la Distribución Comercial, Thomson-Reuters Aranzadi, Navarra, 2010, pp. 369 y ss.

Cuberos De Las Casas, F., Agencia Comercial: entre la comparación y la exégesis, Revista de Facultad de Derecho de la Universidad de los Andes, 2005

De Félix Parrondo, E., "Problemática de la fijación de precios en los contratos entre operadores petrolíferos y estaciones de servicio", Revista de Derecho de la Competencia y la Distribución, La Ley, No 4, 2009, pp. 197 y ss.

De Miguel Asensio, P.A., Contratos internacionales sobre propiedad industrial, $2^{\mathrm{a}}$ ed., Civitas, Madrid, 2000; Domínguez García, M.A. “Aproximación al régimen jurídico de los contratos de distribución. Especial referencia a la tutela del distribuidor”, Revista de Derecho Mercantil, 1985, pp. 419 y ss.

Díaz Echegaray J.L., "El contrato de distribución exclusiva o de concesión", en Bercovitz Rodríguez-Cano, A. / Calzada Conde, Ma. A. (Dir.), Contratos Mercantiles, T. I, Thomson-Reuters Aranzadi, Navarra, 2009, pp. 762 y ss.

Domínguez García, M.A., "Los contratos de distribución: agencia y concesión comercial", en Calvo Caravaca/Fernández De La Gándara (Coord.), Contratos 
internacionales, Tecnos, Madrid, 1997, pp. 1275 y ss.

Domínguez García, M.A., "El contrato de franquicia”, en Bercovitz Rodríguez-Cano, A./Calzada Conde, Ma. A. (Dir.), Contratos Mercantiles, Vol. I, ThomsonReuters Aranzadi, Madrid, 2009, pp. 876 y ss.

Echebarría Sáenz, J.A., El contrato de franquicia, McGraw-Hill, Madrid, 1995

Flaquert Riutort, J., La protección jurídica del agente comercial, Marcial Pons, Madrid, 1999; Galán Corona, E. "Los contratos de distribución. Ideas generales", en Herrero García, Ma. J. (Dir.), La Contratación en el Sector de la Distribución Comercial, Thomson-Reuters Aranzadi, Navarra, 2010, pp. 21 y ss.

Giner Parreño, C.A., Distribución y Libre Competencia (El aprovisionamiento del distribuidor), Montecorvo, Madrid, 1994

Górriz López, C., Distribución Selectiva y Comercio Paralelo, Thomson-Civitas, Madrid, 2007

Hernando Jiménez, A., El contrato de franquicia de empresa, Civitas, Madrid, 2000

Hurtado Palominio, J.V., "Aspectos generales del contrato de agencia comercial en Colombia", en AA.VV., $2^{\circ}$ Congreso Internacional de Derecho Empresarial y Contractual. Organización y Actividad Empresarial, Universidad Santo Tomás Seccional Bucaramanga, octubre 2010, pp. 1/43 y ss.

Iglesias Prada, J.L., "Notas para el estudio del contrato de concesión mercantil", en AA.VV., Estudios en Homenaje a R. Uría, Civitas, Madrid, 1978

Martínez Sanz, F., "En torno a las consecuencias patrimoniales de la extinción del contrato de distribución comercial. (A propósito de la STS, Sala $1^{\text {a }}$, de 27 de mayode 1993", Cuadernos de Derecho y Comercio, 1993, pp. 217 y ss.

Martínez Sanz, F., "Contratos de distribución comercial: concesión y franchising", Scientia Iuridica, 1995, pp. 348 y ss.

Martínez Sanz, F., La distribución a través de agentes y Derecho de defensa de la Competencia, Revista de Derecho Mercantil, 1996

Martínez Sanz, F., La indemnización por clientela en los contratos de agencia y concesión, $2^{\text {a }}$ edición, Civitas, Madrid, 1998

Moralejo Menéndez, I. El contrato mercantil de concesión, Aranzandi, Navarra, 2007; Moralejo Menéndez, I., "El contrato estimatorio", en Bercovitz RodríguezCano, A./ Conde Calzada, Ma- A., (Dir.), Contratos Mercantiles, ThomsonAranzadi, Navarra, 2009, pgs. 582 y ss.

Morales Arias, L.G., "El contrato de agencia mercantil (análisis comparativo entre el derecho colombiano y el derecho anglosajón)", Revista de Facultad de Derecho de la Universidad de los Andes, 1988, pp. 39 y ss.

Muñoz, P.A., "Bases para el análisis de la integración vertical en la distribución comercial", Revista de Derecho Privado y Constitución, 1995, pp. 185 y ss.

Ortuño Baeza, $\mathrm{M}^{\mathrm{a}}$ T., La Licencia de Marca, Marcial Pons, Madrid, 2000

Pardolesi, R. I contratti di distribuzione, Jovene, Napoli, 1979; 
Paz-Ares, C., "La indemnización por clientela en el contrato de concesión”, en AA.VV., Estudios Jurídicos en Homenaje al profesor Justino Duque, T. II, Universidad de Valladolid, Valladolid, 1998, pp. 1287 y ss.

Pellisé De Urquiza, C., Los contratos de distribución comercial, Bosch, Barcelona, 1999

Puente Muñoz, Ma. T., El contrato de concesión mercantil, Montecorvo, Madrid, 1976

Roncero Sánchez, A. El contrato de licencia de marca, Civitas, Madrid, 1999

Sacristán Bergia, F., "Resolución del contrato de concesionario de automóviles y derecho a la indemnización por clientela", Revista de Derecho de la Competencia y la Distribución, La Ley, No 2, 2008, pp. 275 y ss.

Santini, G. El Comercio. Ensayo de economía del derecho, Ariel, Barcelona, 1988

Vaquero Pinto, $\mathrm{M}^{\mathrm{a}} \mathrm{J}$., "Contrato de distribución autorizada o selectiva", en Bercovitz Rodríguez-Cano, R., (Dir.), Tratado de Contratos, Vol. III, Tirant lo blanch, Valencia, 2009, pp. 3190 y ss.

Vaquero Pinto, M ${ }^{\mathrm{a}} \mathrm{J}$., "La terminación de los contratos de distribución”, en Herrero García, Ma. J. (Dir. ), La Contratación en el Sector de la Distribución Comercial, Thomson-Reuters Aranzadi, Navarra, 2010, pp. 313 y ss.; Vergez Sánchez, M., "Compraventa mercantil y contrato de permuta", en Bercovitz Rodríguez-Cano, A./ Calzada Conde, Ma. A., (Dir.), Contratos Mercantiles, Tomo I, ThomsonReuters Aranzadi, Navarra, 2009, pp. 143 y ss.

Vicent Chuliá, F., Introducción al Derecho Mercantil, 20ª ed., Tirant lo blanch, Valencia, 2007 